\title{
(Des)clasificando la cultura escrita guaraní. Un enigmático documento trilingüe de las misiones jesuíticas del Paraguay
}

(De)classifying Guarani Written Culture.An Enigmatic Trilingual Document from the Jesuit Missions of Paraguay

Fabián R. Vega y Guillermo Wilde

\section{(2) OpenEdition \\ Journals}

\section{Edición electrónica}

URL: https://journals.openedition.org/corpusarchivos/2857

DOI: 10.4000/corpusarchivos.2857

ISSN: 1853-8037

\section{Editor}

Diego Escolar

\section{Referencia electrónica}

Fabián R. Vega y Guillermo Wilde, «(Des)clasificando la cultura escrita guaraní. Un enigmático documento trilingüe de las misiones jesuíticas del Paraguay», Corpus [En línea], Vol. 9, No 1 | 2019, Publicado el 02 julio 2019, consultado el 21 junio 2021. URL: http://journals.openedition.org/ corpusarchivos/2857 ; DOI: https://doi.org/10.4000/corpusarchivos.2857

Este documento fue generado automáticamente el 21 junio 2021.

Licencia Creative Commons: Atribución-NoComercial 2.5 Argentina (CC BY-NC 2.5 AR) 


\section{(Des)clasificando la cultura escrita guaraní. Un enigmático documento trilingüe de las misiones jesuíticas del Paraguay}

(De)classifying Guarani Written Culture.An Enigmatic Trilingual Document from the Jesuit Missions of Paraguay

Fabián R. Vega y Guillermo Wilde

\section{NOTA DEL EDITOR}

Fecha de recepción del original: 31/03/2019

Fecha de aceptación para publicación: 17/05/2019

Desde la fundación de las primeras reducciones de guaraníes a principios del siglo XVII hasta mediados del siglo XIX - casi una centuria después de la expulsión de los jesuitas (1767-1768) - se escribieron e imprimieron miles de páginas en diversas lenguas en el territorio misionero. ${ }^{1}$ La cantidad exacta de esta producción es desconocida, pero una estimación preliminar sitúa la porción correspondiente a la lengua guaraní en torno a las ocho mil quinientas páginas (Boidin, 2017, p. 45, vol. III). Estos datos revelan un fenómeno interesante de apropiación y uso de la tecnología de la escritura en diferentes contextos de interacción entre indígenas y agentes de la sociedad colonial y republicana, que conformaron verdaderas "ciudades letradas" en las fronteras iberoamericanas (Boidin, 2017; Cerno y Obermeier, 2013; Couchonnal y Wilde, 2014; Rama, 1984). A la mayoritaria producción escrita en guaraní en las reducciones jesuíticas debe agregarse la prácticamente desconocida producción de los pueblos encomendados o tavas, tutelados por los franciscanos y curas seculares desde fines del siglo XVI. No es un dato menor que el primer texto guaraní del que se tiene conocimiento, el catecismo del franciscano Luis de Bolaños (1550-1629), constituyera un 
modelo para la producción jesuítica posterior (Melià, 2003 [1969], pp. 17-42 y 209-260). Estas influencias no han sido estudiadas hasta el momento, aunque la literatura sobre los pueblos encomendados ha recibido cierta atención en los últimos años (Austin, 2015; Salinas, 2010).

El hallazgo reciente de nuevos documentos manuscritos e impresos en archivos y bibliotecas de América y Europa ha revelado la existencia de una variedad de formas textuales producidas en y para los espacios misioneros fronterizos desconocidas hasta hace poco tiempo. Su análisis presenta un desafío inédito para la etnohistoria y la historia cultural de las fronteras iberoamericanas. Si bien historiadores y bibliógrafos como José Toribio Medina y Guillermo Furlong habían reparado en la existencia de dichos materiales, la mayor parte de la interpretación histórica se hizo prescindiendo de ellos (Furlong, 1962; Medina, 1930). La experticia en la lengua guaraní colonial y el tiempo necesario para la traducción eran dos condiciones imprescindibles con las que la historiografía de la primera mitad del siglo XX no contaba para encarar la tarea. La situación cambió radicalmente con la obra de Bartomeu Melià, quien desde su tesis doctoral (defendida en la Universidad de Estrasburgo en 1969 y publicada tardíamente) no solo superó la mirada hispanofílica predominante, sino que reivindicó el protagonismo indígena y propuso uno de los primeros inventarios de materiales en lengua guaraní (Melià, 1970, 1992, 2003 [1969]). Melià continuó solitariamente esa tarea por numerosas décadas, abriendo caminos para el estudio de la lengua. No fue sino hasta inicios del siglo XXI que una nueva generación de investigadores comenzó a abordar de manera sistemática el estudio del corpus en cuestión, expandiéndolo de manera considerable (Caballos Piñero, 2013; Chamorro, 2009; Otazú Melgarejo, 2006). Al estudio precursor del historiador brasileño Eduardo Neumann (2004, 2005, 2015), interesado en la escritura indígena independientemente de su lengua, se sumaron posteriormente los esfuerzos de equipos interdisciplinarios de Francia, Alemania y Argentina, hoy en plena actividad.

El análisis de las lenguas indígenas coloniales, más conocidas como "lenguas generales", ha contribuido de manera decisiva a la renovación del campo de estudios misionales. Sin embargo, todavía necesita desarrollar un diálogo más estrecho con la historia cultural de las prácticas escritas y las perspectivas renovadoras de la paleografía, cuyo programa viene siendo sistemáticamente establecido desde los años 1990 para el continente europeo de la mano de las investigaciones de Roger Chartier, Armando Petrucci, Fernando Bouza, Antonio Castillo Gómez y otros (Bouza, 1992, 2001; Castillo Gómez, 2002, 2003, 2006; Certeau, 2006; Chartier, 1992, 1996; González Sánchez, 2007; Palomo, 2013; Petrucci, 1999, 2003). Según señala Antonio Castillo Gómez, después de un largo período de indefinición conceptual, el estudio de la cultura escrita comenzó a configurarse como un abordaje integral del circuito de producción, circulación y recepción de textos (manuscritos e impresos). Dicho abordaje tuvo la virtud de combinar el interés por las cualidades técnico-materiales de los textos con el análisis de su contenido y estructura, trascendiendo así "la consideración de la escritura como un mero sistema gráfico para interrogarse principalmente por sus distintas funciones y las consiguientes prácticas materiales" (Castillo Gómez, 2003, p. 96). Entre otras dimensiones, este estudio integral considera el uso de la escritura en cada tiempo y lugar, la distribución de las capacidades y conocimientos para la escritura y la lectura, las materialidades de lo escrito y las formas concretas de su apropiación y recepción. 
4 La definición sintética de Castillo Gómez, ligada al estudio de la cultura escrita europea, y la orientación de las investigaciones de Eduardo Neumann sobre la escritura guaraní dan contornos a un proyecto general de estudio de lo que podríamos llamar la cultura escrita de las misiones en todas sus facetas. ${ }^{2}$ En consonancia con esa orientación, este trabajo se encuadra en un intento más amplio por reconstruir "las conexiones entre las diferentes materialidades de lo escrito de cara a comprender su significado global en una sociedad determinada" (Castillo Gómez, 2003, p. 108). Desde un punto de vista operativo y metodológico, el análisis de esta cultura escrita debe concentrarse en la interrelación de los discursos (los enunciados que reglamentan y regimientan la sociedad), las prácticas (las apropiaciones concretas, individuales o colectivas, de lo escrito) y las representaciones (las imágenes que una sociedad construye sobre sí misma y sobre las prácticas a que da lugar). Asimismo, deben considerar tres tiempos básicos de lo escrito: la producción y adquisición, el uso y apropiación y la conservación. Dicho en los términos más concretos de Petrucci, el objetivo debe ser recuperar la interrelación entre la sociedad y la escritura afrontando el qué, el cuándo, el dónde, el cómo, el quién y el para qué de las prácticas escritas (Petrucci, 2003, pp. 7-9).

5 Tanto la cultura escrita como sus múltiples mediaciones y funciones constituyen una vía de acceso a la praxis cotidiana misional y sus proyecciones. En este sentido, las misiones jesuíticas del Paraguay formaron parte de una constelación mayor de establecimientos controlados por la orden en todo el espacio rioplatense y sudamericano, junto a los pueblos franciscanos de la misma región. El crecimiento acelerado de la orden a nivel global conllevó la configuración de un sistema de informaciones que conectaba dichos establecimientos y aseguraba las comunicaciones con las sedes metropolitanas ubicadas en las principales ciudades de la región y Europa (Clossey, 2008; Friedrich, 2008). Una parte central del sistema administrativo jesuítico consistió en la producción y circulación de textos en una diversidad de géneros y formatos que se adaptaban tanto a los códigos de la circulación regional, atlántica y global como a las necesidades prácticas que los misioneros enfrentaban en diferentes espacios geográficos (Wilde, 2018). Desde sus inicios, la orden jesuita desarrolló estrategias específicas de escritura altamente reglamentadas (Morales, 2011) e instrumentos para la clasificación y ordenamiento de su producción textual, creando bibliotecas y archivos para acumular una suerte de memoria escrita en todos los lugares donde desenvolvió actividades (Vega, 2017, 2018). Por otra parte, la cultura escrita de las regiones de misión desplegó formas propias que resultaron de la interacción entre misioneros e indígenas.

6 A nivel local, un instrumento clave de dicha producción textual fue la llamada "reducción" lingüística, consistente en la selección y estandarización de determinadas variantes de la lengua indígena con el objetivo de elaborar textos para la trasmisión de las ideas básicas de la religión cristiana y de facilitar la comunicación entre los indígenas y los misioneros (Estenssoro, 2015; Estenssoro e Itier, 2015; Melià, 2003 [1969]). El proceso de "reducción" lingüística tendió a homogeneizar y formalizar registros básicos de comunicación ligados a la función administrativa y religiosa de los pueblos de misión. La escritura, una tecnología inexistente en los contextos indígenas anteriores al contacto colonial en la región, progresivamente se transformó en una práctica extendida en esos espacios. La investigación más reciente ha demostrado que los miembros de la élite indígena misional participaron de manera directa en el proceso 
de producción y circulación de textos en lengua guaraní (Neumann, 2015, pp. 67-97; Wilde y Vega, 2019).

7 Hasta el momento no contamos con un inventario integrado de la cultura escrita misional. Sin embargo, los numerosos ejemplos dispersos en archivos y bibliotecas de América y Europa revelan un entramado complejo de producciones realizadas en y para las misiones, que circularon por el espacio continental y atlántico y cuyas funciones sociales resultan todavía poco conocidas. En este sentido, el material encontrado hasta el momento permite identificar diferentes situaciones ligadas a la cultura escrita en los espacios misionales que incluyen: a) textos en guaraní y español producidos por los miembros de la élite indígena dentro de las misiones; b) textos en lengua guaraní resultantes de la colaboración entre misioneros jesuitas y miembros de la élite indígena; c) textos impresos fuera de las misiones orientados a la tarea misional (en español, guaraní e incluso latín); d) textos circulantes entre diferentes establecimientos jesuíticos (producidos dentro y fuera de las misiones), manuscritos e impresos, existentes en las bibliotecas o "librerías" de las orden.

8 Esta aproximación panorámica resulta útil como punto de partida. Sin embargo, al acercar la lupa al material concreto se imponen matices y singularidades que dificultan una clasificación tajante. La élite indígena no desarrolló homogéneamente la escritura ni adquirió competencias gráficas en su totalidad. Contó con agentes especializados escribientes y profesionales de la escritura en la terminología de Petrucci (2003, pp. 27-40)-, como los indígenas vinculados a la Iglesia y las congregaciones religiosas o cofradías, que desarrollaron géneros específicos de escritura con una orientación "espiritual" (Wilde, 2017). Por otra parte, los cabildos indígenas incluyeron secretarios o escribanos especializados que asumían la función escritural por delegación. La autoría, cuando no está rubricada por los mismos indígenas -como suele suceder en el caso de los documentos de gobierno o jurídicos-, es muy difícil de establecer. Buena parte del corpus convencionalmente llamado "espiritual" puede atribuirse a una autoría múltiple, es decir, a la colaboración entre los sacerdotes y los indígenas (Brignon, 2018). Incluso textos explícitamente reconocidos como pertenecientes a un autor, como el famoso Explicacion de el catechismo en lengua guaraní (1724) de Nicolás Yapuguay, no excluyen la colaboración o supervisión del sacerdote.

9 A su vez, el involucramiento de los jesuitas en la producción de escrituras en la lengua indígena es patente y obvio en el caso de textos directamente vinculados a la actividad pastoral como los catecismos, vocabularios y gramáticas, y presumible en muchos otros en los que la tradición europea es determinante, como ciertas obras asociadas a la espiritualidad ignaciana o a la tratadística médico-botánica (Obermeier, 2018). Sin embargo, en géneros como los sermones predomina un importante grado de ambigüedad con respecto a la producción y la recepción que hace difícil definir atribuciones y destinatarios.

10 También se presentan situaciones textuales prácticamente imposibles de estandarizar, como las que representan documentos que no encajan en ningún tipo o género conocido y cuya pragmática resulta difícil de inferir. Este artículo está dedicado, metafóricamente, a la "desclasificación" de uno de esos documentos. Entendemos la acción de desclasificar en el doble sentido de darlo a luz, como se revelaría un escrito "secreto", y de señalar su carácter específico, no susceptible de insertarlo en una clasificación o tipología preestablecida. Se trata de un pequeño papel con fragmentos en guaraní, español y latín, encontrado en el Archivo General de la Nación de Buenos 
Aires, Argentina. Nos detendremos en un análisis del contenido de esta fuente y trataremos de entender sus posibles usos en la cultura escrita y más ampliamente en la praxis político-religiosa de los pueblos de misión. A nuestro entender, este escrito señala una imbricación entre la dimensión espiritual y temporal de la vida misional y da indicios de lo que pudo ser el desenvolvimiento de la performance verbal en esos espacios, íntimamente ligada a las prácticas devocionales. Esto nos llevará, en un segundo momento, a vincular el documento con una constelación mayor de escrituras personales todavía desconocido para la cultura misional. Cabe resaltar el carácter ambiguo de esta fuente, que al tiempo que señala su pertenencia al género políticoespiritual junto con otros textos de la época, también indica su carácter único y sui géneris, manifestación de una multiplicidad irreductible de la cultura escrita misional.

11 Es necesario aclarar que el estudio del corpus textual en su complejidad, dinámica y tensiones internas permite reconstruir e interpretar situaciones concretas de la praxis cultural que exigen el trabajo conjunto de lingüistas e historiadores. Esta empresa de análisis presenta al menos dos problemas de orden teórico-metodológico que es necesario explicitar. El primero se relaciona con la dificultad de reconstruir las múltiples mediaciones entre el texto concreto y su contexto de producción, circulación y recepción, es decir, las prácticas culturales de las que es indicio. Los documentos están atravesados tanto en su dimensión textual como material por circunstancias opacas, solo parcialmente recuperables a través de operaciones técnicas de reconstrucción lingüística y bibliográfica. En este sentido, la comprensión plena del texto en su contenido lingüístico no alcanza para inferir sus posibles usos, las circunstancias que lo originaron y el conjunto de prácticas sociales, políticas y culturales sobre las que informa. La relación conjetural entre rastros documentales o lingüísticos y prácticas históricas exige entonces el cruce de fuentes y discursos de diferente tipo producidos en el contexto misional (incluso libros de cuentas, inventarios o listas), independientemente de la lengua en la que hayan sido formulados.

El segundo problema, derivado del anterior, se asocia al universo de la cultura escrita como objeto de investigación. La fascinación por los documentos en lengua guaraní tiende a hacer perder de vista que estos solo fueron una porción de un universo textual, material y escrito mucho más amplio, dentro del cual adquirieron sentido. Para evitar que el árbol impida ver el bosque, es necesario remitirse al entramado envolvente de prácticas textuales y culturales (desde la escala micro hasta la regional, e incluso atlántica y global), sentido último de una historia y una antropología culturales.

Este artículo se divide en cuatro partes. La primera aborda las características materiales específicas del documento. La segunda se centra en el análisis del contenido de cada uno de los fragmentos en las tres lenguas. Las tercera y cuarta partes buscan situar el escrito respectivamente en sus posibles contextos de uso y su trama intertextual. Al tiempo que señalamos las características singulares de este enigmático papel, buscamos encontrarle sentido dentro de un corpus más general y amplio. Muchas de las afirmaciones sugeridas aquí tienen carácter conjetural y están destinadas a provocar reacciones entre los especialistas del mundo guaraní, la historia colonial iberoamericana, la historia de la cultura escrita, y la historia y antropología cultural en general. 


\section{¿Una aguja en un pajar? Un rarísimo documento del Archivo General de la Nación}

El documento que analizaremos es un pequeño escrito trilingüe conservado en un legajo misceláneo de papeles jesuíticos del Archivo General de la Nación de Argentina (en adelante AGN) (véanse Imágenes 1, 2, 3 y 4). ${ }^{3}$ No existe ninguna mención de esta fuente en la historiografía especializada ni en ningún catálogo documental. Esto probablemente se deba a sus dimensiones: se trata de un escrito minúsculo, de un folio de extensión. A primera vista, el componente significativo reside en la faceta lingüística: lleva escritas frases en español, latín y guaraní, sin una jerarquía manifiesta de ninguna de esas lenguas entre sí. Aunque el caso parezca excepcional, la copresencia de estas tres lenguas fue un fenómeno que contó con algunos ejemplos notables en la literatura misionera. El más significativo es probablemente un fragmento del teatro misional conservado oralmente como el "Drama de Adán" (Dreidemie, 1937, pp. 70-73). ${ }^{4}$ Los libros escritos por Nicolás Yapuguay, Explicacion de el catechismo en la lengua guarani (1724) y Sermones y exemplos en la lengua guarani (1727), también poseen expresiones en los tres idiomas, aunque el guaraní es abiertamente predominante. Como sea, se trata de casos aislados que resaltan la singularidad de la construcción lingüística del documento que nos ocupa. A esto se suma otro rasgo material relevante: pueden percibirse pliegues en el papel, los cuales dan cuenta de que fue doblado deliberadamente para formar un diminuto rectángulo.

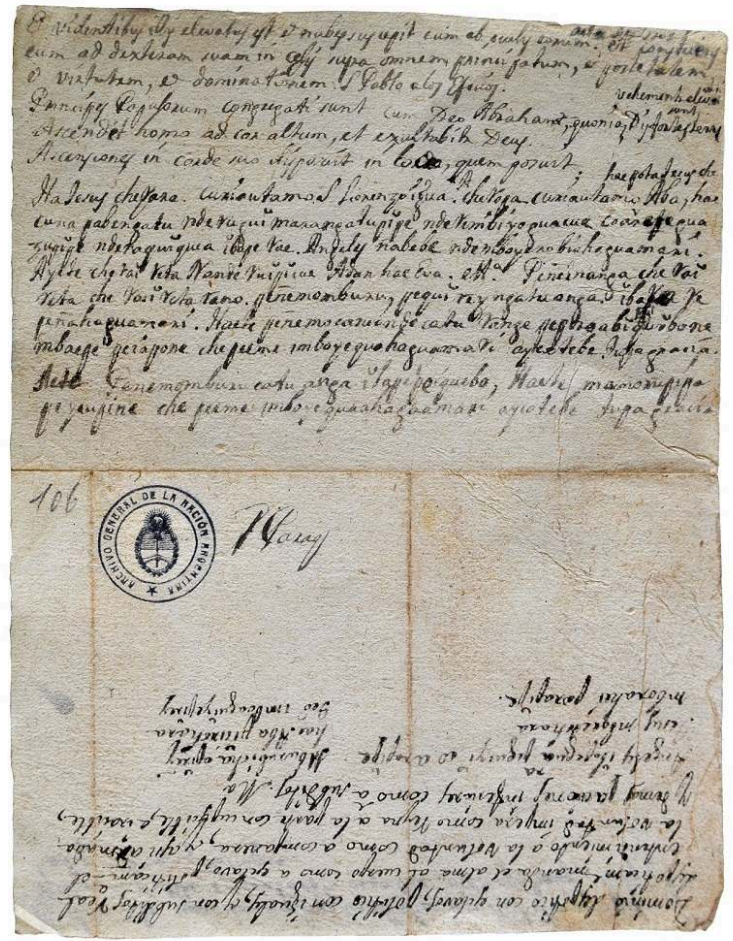

Imagen 1. Primera y segunda caras del documento, desplegado tal y como existe en el AGN actualmente. 


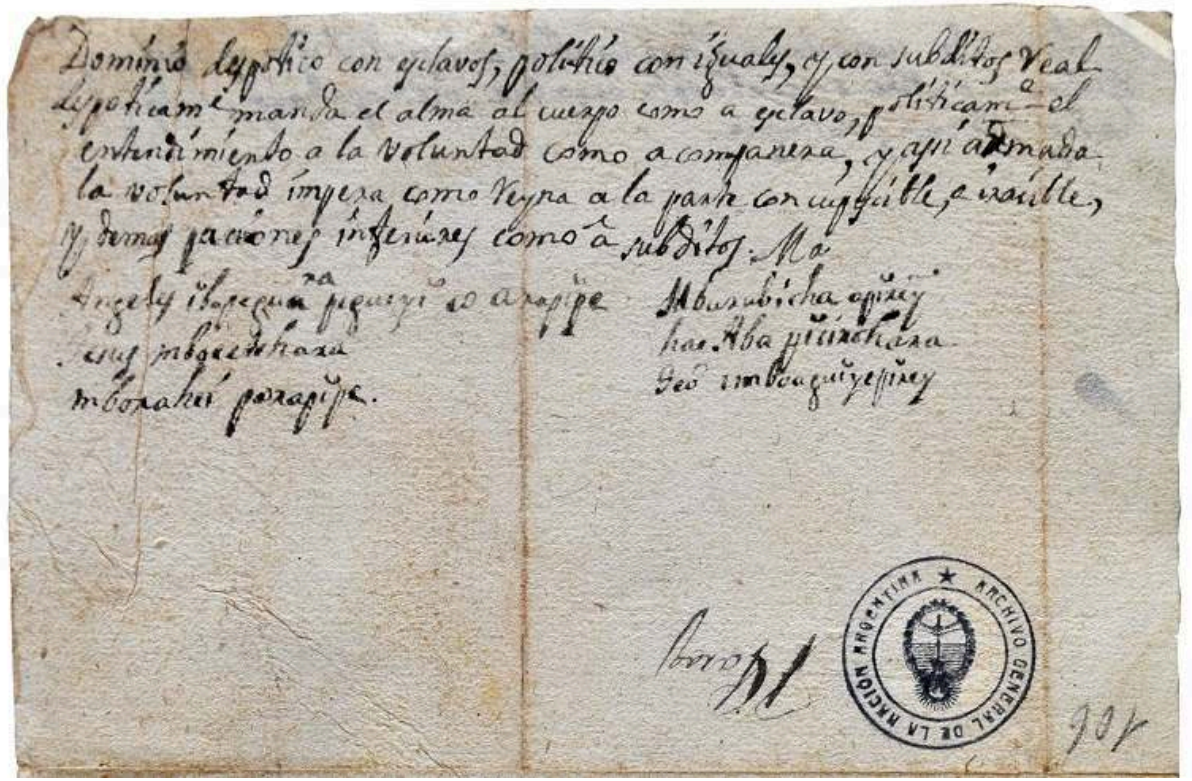

Imagen 2. Detalle de la primera cara del documento.

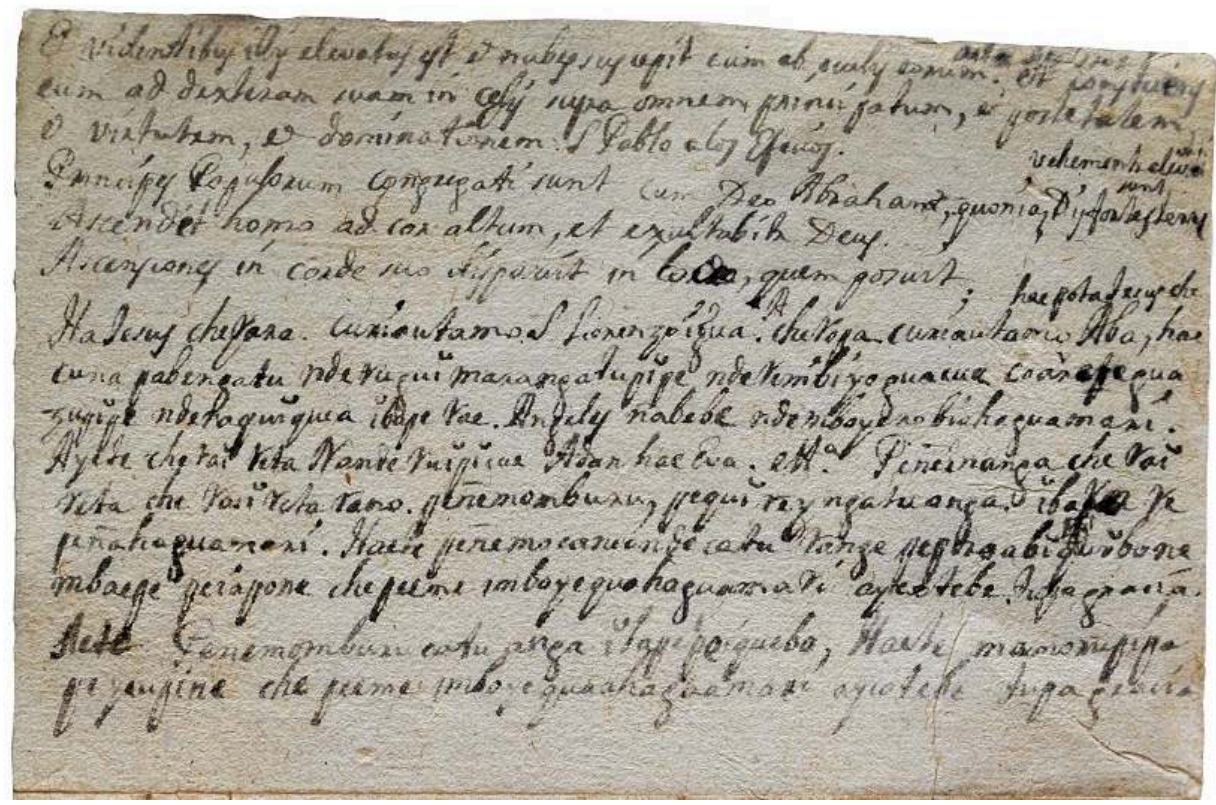

Imagen 3. Detalle de la segunda cara del documento. 


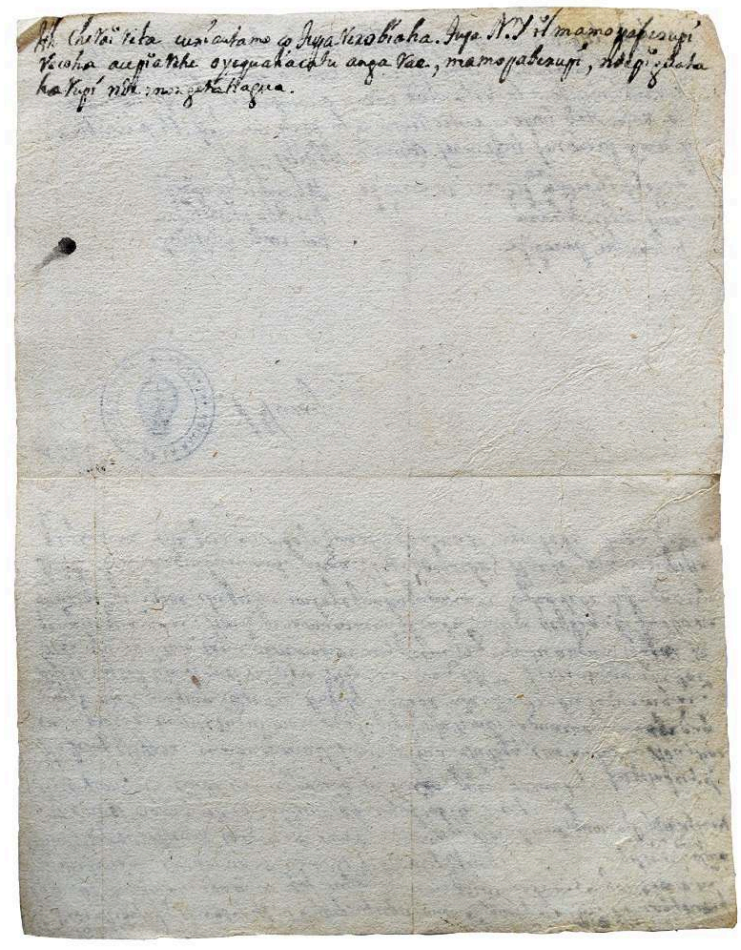

Imagen 4. Tercera y cuarta caras del documento, anverso de la primera y la segunda caras respectivamente.

15 Se encuentra en buen estado de conservación y, desde luego, está escrito a mano. Carece de indicaciones precisas de fecha y lugar. Solamente aparece una aclaración archivística, "P. Paraq.", probablemente escrita en latín para referir a la provincia jesuítica del Paraguay, que incluía las misiones de guaraníes pero también otras misiones y varias residencias y colegios urbanos. Además, lleva plasmado un sello del archivo actual y una numeración, "106", que corresponde a la sucesión original de los documentos en el legajo, que careció siempre de encuadernación (quizás por eso actualmente se encuentran desordenados). Dentro del AGN, el documento forma parte del Fondo Compañía de Jesús. Como se indica en un libro de este archivo compilado por Juan Pablo Zabala, la "mayor parte de los documentos [de este fondo] provienen de los archivos de los conventos, colegios y misiones" de los jesuitas de la provincia del Paraguay y pasaron a formar parte de las instituciones archivísticas en la primera mitad del siglo XIX (Zabala, 2011, p. 290). A principios del siglo XX se dio al fondo el actual ordenamiento cronológico. Al carecer de fecha, esta fuente fue confinada a un legajo de documentación miscelánea, de diversos años, poco utilizado en la investigación.

En cualquier caso, el origen geográfico del escrito no genera dudas. Al contener un texto manuscrito en lengua guaraní colonial, se infiere que fue producido en el espacio en que esta lengua era hablada: las misiones de los ríos Paraná y Uruguay o las ciudades de Asunción y Corrientes. La producción textual en el guaraní acriollado de Corrientes y Asunción es escasa. Esto hace más probable (aunque no seguro) que el documento formase parte de la heterogénea cultura escrita del territorio jesuítico-guaraní. Una pequeña referencia en el fragmento guaraní da indicios de que podría provenir de la reducción de San Lorenzo (actualmente Rio Grande do Sul, Brasil) o sus cercanías. No 
resulta visible la filigrana del papel -que podría permitir rastrear su procedencia-, sino tan solo su contramarca, que consiste en una letra "A" inscrita en un óvalo de aproximadamente 3,3 cm de largo por 1,1 de alto (véase Imagen 5). No obstante, el papel utilizado en las misiones provenía por lo general de Europa. Aunque los jesuitas pensaron en establecer una fábrica local de papel, parece que este nunca llegó a producirse, ni siquiera en el contexto del funcionamiento de la imprenta en las primeras décadas del siglo XVIII (Furlong, 1962, pp. 587-588).

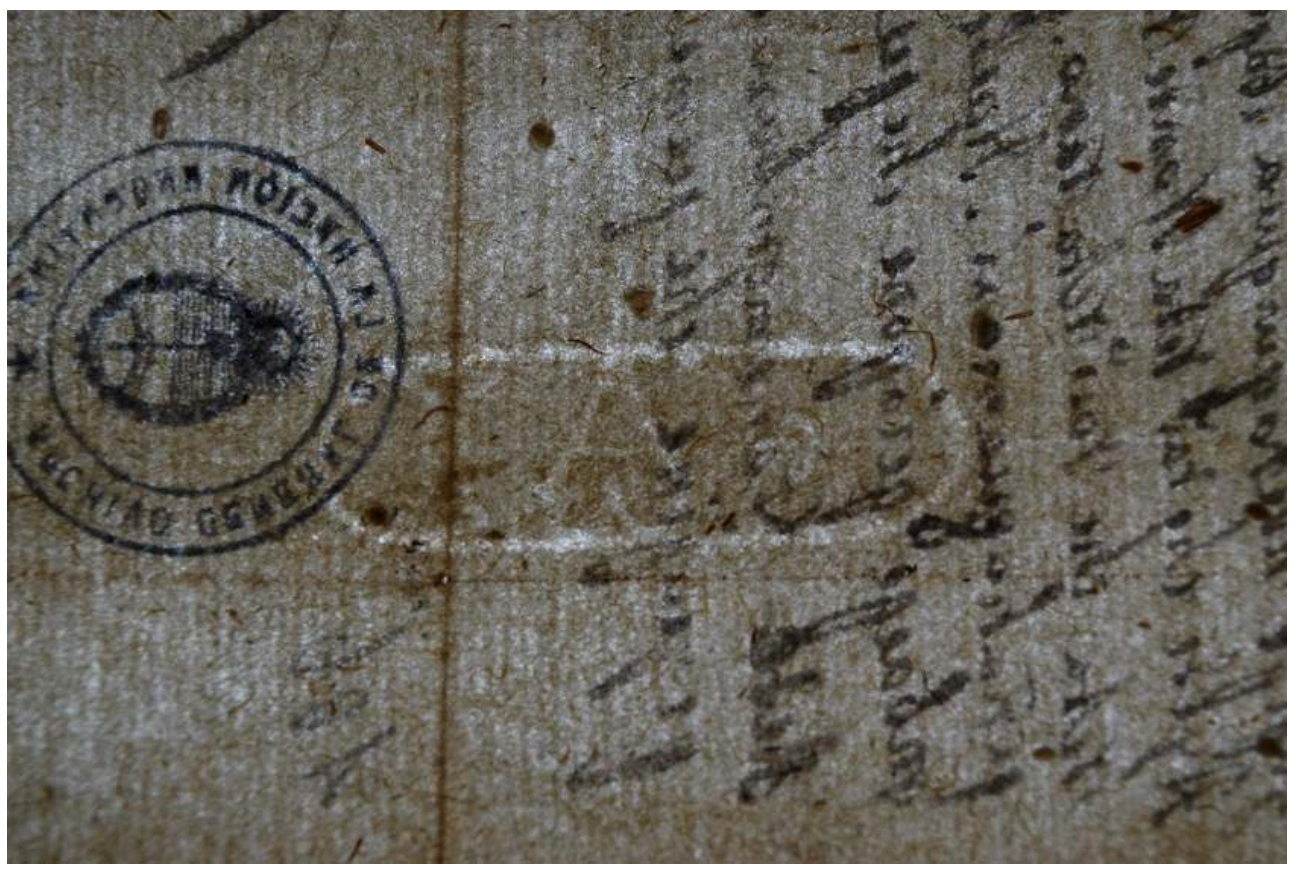

Imagen 5. Contramarca de la filigrana del papel, " $A$ " inscrita en un óvalo.

17 La datación temporal del documento es más ambigua. Como lo señalaremos más adelante, una parte del escrito transcribe un fragmento de un libro jesuita publicado por primera vez en España en 1681. Así, el tiempo de producción del documento parece corresponder al amplio período que va de 1681 a 1767-1768, cuando los jesuitas fueron expulsados de los territorios de la monarquía hispánica. Esta inferencia coincide con la información ya conocida que indica que en esos ochenta años se desarrollaron las muestras más importantes de la cultura escrita jesuítica en lengua guaraní (Cerno y Obermeier, 2013; Vega, 2018, pp. 12-19; Wilde, 2014). Más allá de estos indicios, no resulta posible identificar quién o quiénes fueron los productores concretos de este papel, quién o quiénes los destinatarios -si es que los había- o cuáles las circunstancias concretas de realización.

18 Aunque ameritaría una indagación más profunda, un análisis preliminar indica que la misma mano intervino en la producción de los distintos fragmentos del documento. En general, la caligrafía de las caras parece ser la misma. Sin embargo, se percibe que la intervención se realizó en distintos tiempos, de lo que da indicios la conservación variable de la intensidad de la tinta en los distintos fragmentos. ${ }^{5}$ Por ejemplo, en la primera cara, el texto en guaraní fue escrito en una tinta actualmente más clara que el resto, mientras que lo opuesto sucede en la segunda cara.

19 Otro aspecto material central son los pliegues aún perceptibles en el papel, a partir de los cuales es posible reconstruir el proceso de plegado del documento. En la Imagen 6 se representa, a través de una visualización artificial, este proceso de plegado, que 
permite observar la forma del documento, después de ser doblado varias veces sobre sí mismo. El papel se dobló a la mitad, cubriendo por completo lo que hemos llamado tercera cara y convirtiéndose la primera y la segunda caras en una suerte de "cubiertas". Posteriormente, se realizaron dos nuevos dobleces "hacia adentro" de la segunda cara. El resultado es que un papel ya de por sí bastante pequeño (de aproximadamente 17,5 por $13,5 \mathrm{~cm}$ ) acabó convirtiéndose en un rectángulo diminuto (de aproximadamente 8,7 por $6 \mathrm{~cm}$ ). Ningún fragmento completo podía ser leído con el papel plegado, pero probablemente el objetivo de los dobleces fuese transportar el documento o conservarlo en un espacio reducido. ${ }^{6}$

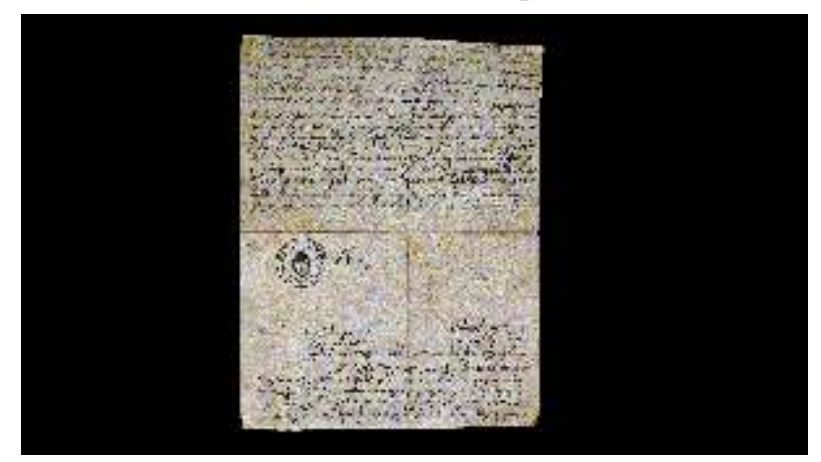

Imagen 6. Representación artificial del proceso de plegado del documento. Agradecemos a M. Matilde Rodríguez la realización de esta representación gráfica. Ver archivo adjunto.

En cuanto al texto mismo, a pesar del carácter excepcional del papel, existen varias dimensiones que permiten encuadrarlo, puesto que concentra las características centrales de la cultura escrita de las misiones tal y como la conocemos. En este sentido, el contenido de los fragmentos, sumado a las características materiales explicitadas, provee indicios para el estudio de la praxis histórica misional.

\section{Contenido del texto trilingüe}

21 El documento está escrito en tres lenguas distintas, divulgadas en el espacio misional: español, guaraní y latín. En las reducciones, la comunicación cotidiana y religiosa (como sermones y confesiones o la recitación del catecismo) entre jesuitas e indios se realizaba en guaraní. Algunos componentes ceremoniales de la liturgia católica, como ciertos cánticos de la misa o la formulación discursivo-ritual de los sacramentos, podían estar en español o en latín. Un sector de las élites indígenas aprendía a cantar y leer aunque no necesariamente a entender- estos idiomas para cumplir las funciones religiosas. Más allá de esto, los indios se comunicaban entre sí en guaraní y los jesuitas hacían lo propio en latín o más comúnmente en español. ${ }^{7}$ La investigación lingüística ha mostrado también que hubo más de un registro de la lengua guaraní: el cotidiano, hablado o coloquial, y el ritual, más formalizado, generalmente estandarizado en textos gramaticales para el estudio de los sacerdotes y ligado a la actividad litúrgica (Cerno y Obermeier, 2013). El documento a analizar contiene cuatro fragmentos distintos: tres en guaraní, otro en español y el último en latín. Comprende así el entramado de las formas comunicativas que tenían lugar en la misión. 


\section{Los fragmentos en guaraní}

El segundo fragmento es más largo y complejo (véase Imagen 8). Dice lo siguiente:

Los fragmentos en guaraní aparecen intercalados con las partes en español y latín, en ambas caras del documento (véanse la transcripción al final del artículo y las Imágenes 1, 2, 3 y 4). Para facilitar el análisis procedemos a transcribirlos íntegramente a continuación y a proponer una primera traducción o interpretación. Cabe aclarar que esta primera aproximación al texto guaraní no es absolutamente literal. Para facilitar la lectura hemos omitido la inclusión de glosas morfológicas, las cuales podrán ser eventualmente reconstruidas por los lingüistas. Ocasionalmente se harán aclaraciones ligadas a diferentes traducciones utilizadas para un mismo vocablo.

El primer fragmento se lee en dos columnas (véase Imagen 7). La primera dice:

Angeles ǐbapegua ${ }^{\text {ra }}$ pegueyĭ co arap̌pe

Jesus mbaeete hara

mborahei porapı̌pe.

'Ángeles del cielo bajad en este día.

Jesús generoso

Cantad $^{8}$ en alabanza'.

En la segunda columna, a la derecha, se lee:

$\mathrm{Ma}^{9}$

Mburubicha ap̌reỹ

hae Aba přcirohara

Teô imboagulyepirrey

'Eterno Todopoderoso.

salvador de los hombres.

de quien derrota eternamente a la muerte'. ${ }^{10}$

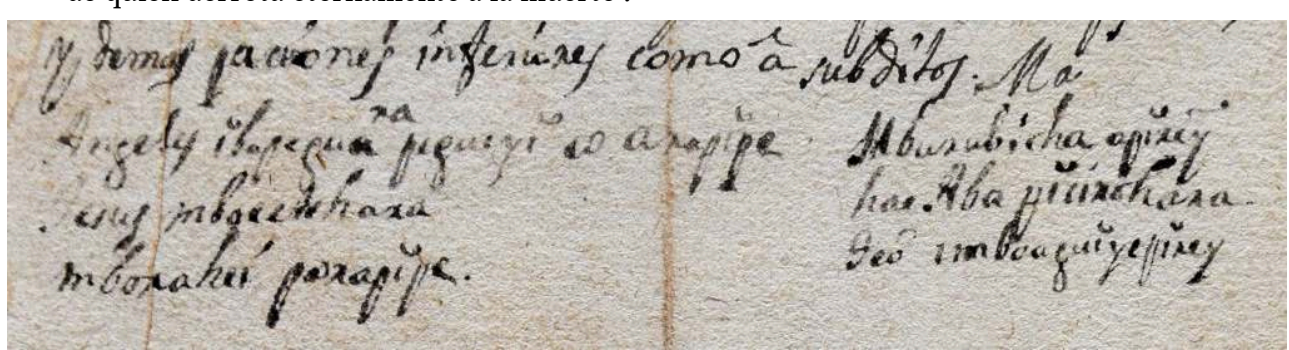

Imagen 7. Detalle del fragmento en guaraní de la primera cara del documento, dividido en dos columnas.

Ha Jesus cheyara. curiautamo S. Lorenzo igua. [Arriba: A] cheropa. ${ }^{11}$ curiautamo Aba, hae / cuna pabengatu nderuguı̆ marangatu pippe nderembiyoguacue co [Arriba: hae pota Jesus che] arete gua / zup̌pe ndehaguĭqua rbape rae. Angeles ñabebe ndemboyerobiahaguamari. / Ayete cheraĭ reta Nande ruĭpřcue Adan hae Eva. Ma $^{a}$. Peñeinanga cheră / reta che rasĭ reta ramo. peñemomburu, pequĭ rey ngatu anga. iba[g]a re / peña haguamari. Haete peñemocanionde catu range peporoab̆ quíbone / mbaepe peiapone che peeme imboyequahaguamari aycotebe tupa gracia / hebe Penemomburu catu anga ibape pequebo, Haete mamorupipa / peyaupine che peeme imboyequaahaguamari aycotebe tupa gracia

'Oh Jesús mi señor. Ojalá me pierda de los sanlorenzanos. ${ }^{12}$ Ojalá todos los hombres y / mujeres por tu sangre santa en estas Pascuas ${ }^{13}$ (es deseo de mi Jesús) / vayan al cielo detrás de ti, volando como ángeles para adorarte. / Mis hijos, Adán y Eva son en verdad nuestros santos ${ }^{14}$ antepasados. ¡Ea, mis hijos / e hijas, ejercitaos para alcanzar el cielo, / esforzaos, daos maña / en todas las actividades que vayáis a hacer $!^{15}$ Para que os explique a vosotros, necesitaría de la gracia de Dios. / 
¡Ejercitaos para alcanzar el cielo! Pero para todas las cosas / que yo os explicaría, necesitaría de la gracia de Dios'.

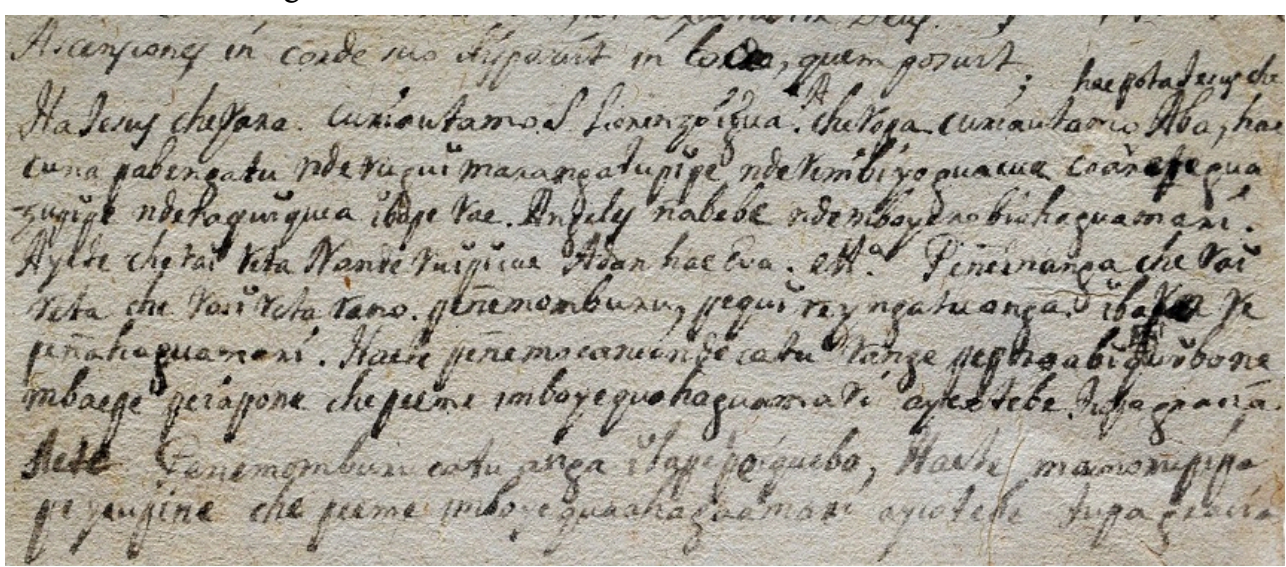

Imagen 8. Detalle del fragmento en guaraní de la segunda cara del documento.

El tercer y último fragmento, muy breve, dice lo siguiente (véase Imagen 4):

Ah cheră reta curiauramo co tupa. rerobiaha. tupa. N.Y ĭt mamo paperupi / recoha ace pra rehe oyequahacatu anga rae, mamopaberupi, ndeprguata / ha rupi nde mongeta Hagua.

¡Ah, mis hijos, sed fieles! Dios Nuestro Señor con cuidado, no importa dónde estemos, / se manifiesta en nuestro corazón, como bien se sabe se presenta por todas partes, por los pasos de tus pies, / para hablarte'.

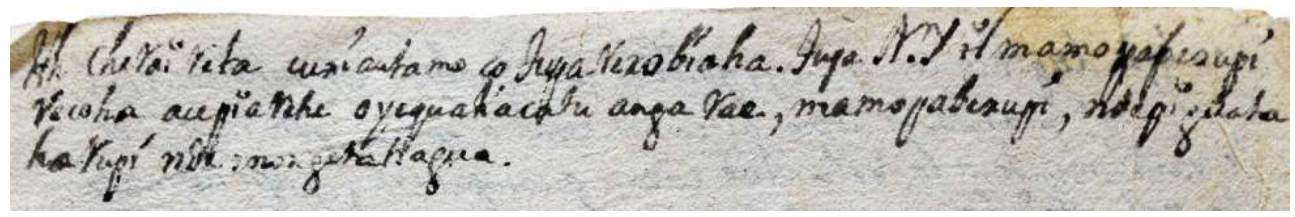

Imagen 9. Detalle del fragmento en guaraní de la tercera cara del documento.

Como puede verse, los fragmentos presentan varios tipos de intervenciones: invocaciones, oraciones, exhortaciones, advertencias. El primero contiene invocaciones a los ángeles, Dios y Jesucristo, similares a jaculatorias. Así, por ejemplo, se invoca a los ángeles (Angeles ỉbapegua ra peguey̆ co arapĭpe, 'Ángeles del cielo bajad en este día'), se alaba a Jesús (Jesus mbaeete hara, 'Jesús generoso') y se da cuenta del carácter performativo de estos enunciados (mborahei porapipe, 'Cantad en alabanza'). Este primer fragmento parece haberse constituido de frases recortadas, sin un encadenamiento claro. Su asociación a una práctica oral es evidente, pero no podemos vincular las frases a ninguna de las oraciones cristianas tradicionales cuya traducción al guaraní colonial es conocida.

El segundo fragmento comienza también por una invocación a Jesús en primera persona (Ha Jesus cheyara, 'Oh Jesús mi Señor'), pero en un determinado momento introduce interlocuciones a un presunto público o exhortaciones a los "fieles", con la indicación de que se esfuercen por llevar una vida buena para alcanzar la salvación. En este sentido, es compatible con otra práctica oral, la del sermón: Peñeinanga cheraĭ reta che rasĭ reta ramo. peñemomburu, pequĭ rey ngatu anga. ïba[g]a repeña haguamari, ‘ ${ }^{\mathrm{E}} \mathrm{a}$, mis hijos e hijas, ejercitaos para alcanzar el cielo'; Penemomburu catu anga ỉbape pequebo, ‘Ejercitaos para alcanzar el cielo!'. El tercer fragmento probablemente deba interpretarse en un sentido similar, aunque en este el aspecto de la manifestación quizás la llegada- de Dios aparece más acentuado: tupa. N.Y it mamo paperupi recoha ace 
pĭa rehe oyequahacatu anga rae, mamopaberupi, ndepı̆guata ha rupi nde mongeta Hagua, 'Dios Nuestro Señor con cuidado, no importa dónde estemos, se manifiesta en nuestro corazón, como bien se sabe se presenta por todas partes, por los pasos de tus pies, para hablarte'. En esta parte se sostiene la insistencia en que los fieles se mantengan en el recto camino del cristianismo (Ah cheraĭ reta curiauramo co tupa. rerobiaha, ' $\mathrm{i} A \mathrm{~h}$, mis hijos, sed fieles!'). Puede incluso tenderse una asociación de este fragmento con un tema promovido de diversas maneras en las misiones, la preparación para la "buena muerte", frecuentemente reflejado en la espiritualidad ignaciana y en el topos textual y visual de las postrimerías y el Juicio Final.

Como lo indicamos, los fragmentos en guaraní dan un solo indicio de la posible procedencia del documento o el autor del mismo: la reducción de San Lorenzo o los pueblos vecinos. La frase curiautamo S. Lorenzo igua. [Arriba: A] cheropa, 'Ojalá me pierda de los sanlorenzanos', aunque extraña y oscura, puede llegar a considerarse la única referencia a un lugar preciso. ${ }^{16}$ La contextualización del documento exige, por un lado, identificar la intensidad comparativa de la actividad devocional en ciertos pueblos $\mathrm{y}$, por el otro, la presencia de estilos diferenciados de habla. Hasta el momento, carecemos de una estadística de la producción escrita de cada reducción en el gran espacio misional. Pero algunos testimonios señalan que ciertos pueblos fueron usinas de estilos particulares de habla, no generalizados en otros. ${ }^{17}$ Asimismo, es evidente que, en el marco de la cultura escrita guaraní, algunas reducciones destacaron sobre las otras en cuanto a la cantidad -y probablemente también la calidad- de su producción, lo que podría dar indicios para situar este documento. San Nicolás o San Francisco Javier destacaron en este punto sobre otros. ${ }^{18}$

El documento requeriría un abordaje específico de los aspectos lingüístico-filológicos que por el momento no estamos en condiciones de realizar. Sin embargo, la asociación con otros documentos permite señalar algunos rasgos en este sentido también. Para empezar, debe destacarse que las expresiones que se utilizan en el segundo y tercer fragmentos para referir a los "fieles" son las formas comunes en que los jesuitas solían dirigirse a la población indígena (Boidin, Cerno y Vega, en prensa). Esto reforzaría la idea de que por lo menos estas secciones formaban parte de una orientación sermonística más amplia, probablemente ejercida por un sacerdote o un miembro de la élite indígena. ${ }^{19}$ Cabe añadir que el texto presenta una serie de rarezas filológicas, según la opinión del colega lingüista Leonardo Cerno. Una de ellas es el uso de la "z" en reemplazo de la "ç", cambio introducido en la grafía de la lengua guaraní misional no antes del siglo XVIII. Aunque existen evidencias de este uso en la obra del jesuita Pedro Montenegro, no es hasta el año de 1759 en que se consolida. Este dato podría servir para situar temporalmente el documento en algún momento en torno a mediados del siglo XVIII. Otra rareza es que ciertos fragmentos parecen indicar la mezcla de expresiones de posible traducción española con otras más estrictamente representativas de la tradición guaraní. A este último aspecto se debe la gran dificultad de traducción de los fragmentos y el carácter singular de este papel. Una vez realizada la "desclasificación" del documento, los especialistas en la lengua podrán contribuir a resolver los problemas aquí planteados.

\section{El fragmento en español}

Dominio despotico con esclavos, politico con iguales, y con subditos real / despoticamente manda el alma al cuerpo como a esclavo, politicamente el / 
entendimiento a la voluntad como a compañera, y assi armada / la voluntad impera como reyna a la parte concupiscible, e irascible, / y demas paciones inferiores como a súbditos.

El fragmento en español es el más extenso de todos y está escrito en la misma cara que uno de los textos en guaraní. Aunque no hay ninguna referencia, se deduce que se trata de una cita de un libro del jesuita Francisco Garau. Este nació en Girona (Cataluña) en 1640 , ingresó a la Compañía de Jesús en 1655 , fue censor inquisitorial y rector de varios colegios de la región y murió en Barcelona en 1701 (Bernat Vistarini, 2000, 2002; Bernat Vistarini y Cull, 2017; Cull y Bernat Vistarini, 2010; Sommervogel, 1892, pp. 1194-1198). Escribió dos series de libros de literatura emblemática, El sabio instruido de la naturaleza y El sabio instruido de la Gracia. El fragmento citado en el documento proviene del segundo volumen de la primera serie, titulado El Olimpo del sabio instruido de la naturaleza y segunda parte de las máximas políticas y morales. Este libro tuvo varias ediciones; la primera definitiva es de $1690,{ }^{20}$ existiendo una anterior incompleta de $1681 .{ }^{21}$ Gracias a la cita se puede inferir con seguridad que el documento no se escribió antes de las décadas finales del siglo XVII. Sin realizar una exploración exhaustiva, en las bibliotecas de las misiones se encuentran libros del autor en Apóstoles (2 volúmenes), Candelaria (15), Concepción (2), Itapúa (2), Mártires (7), San Cosme (2), San Ignacio Miní (3), San José (5), San Juan (5), San Lorenzo (9), Santo Ángel (6) y Yapeyú (3). ${ }^{22}$ Nótese que, fuera de la biblioteca central de Candelaria -que poseía casi la mitad de los volúmenes de todas las reducciones-, San Lorenzo es la reducción que más libros de Garau tiene (véase Imagen 10). En la mayoría de estos casos no se menciona con precisión el título, pero El sabio instruido de la naturaleza (o derivados similares) aparece registrado en, por lo menos, dos ocasiones. Este autor estaba distribuido fuera de las reducciones, en los colegios jesuíticos; había por ejemplo 6 volúmenes en Córdoba (Fraschini, 2005, p. 232) y 18 en Asunción (Gorzalczany y Olmos Gaona, 2006, p. 153; Telesca, 2009). También es común encontrarlo en otras bibliotecas jesuíticas americanas, como las de Baja California (Mathes, 1991, pp. 384, 415) y la de Antioquia (Rey Fajardo y Mora, 2008, p. 232). Se trataba de un autor ampliamente divulgado y leído en la Compañía de Jesús en el continente.

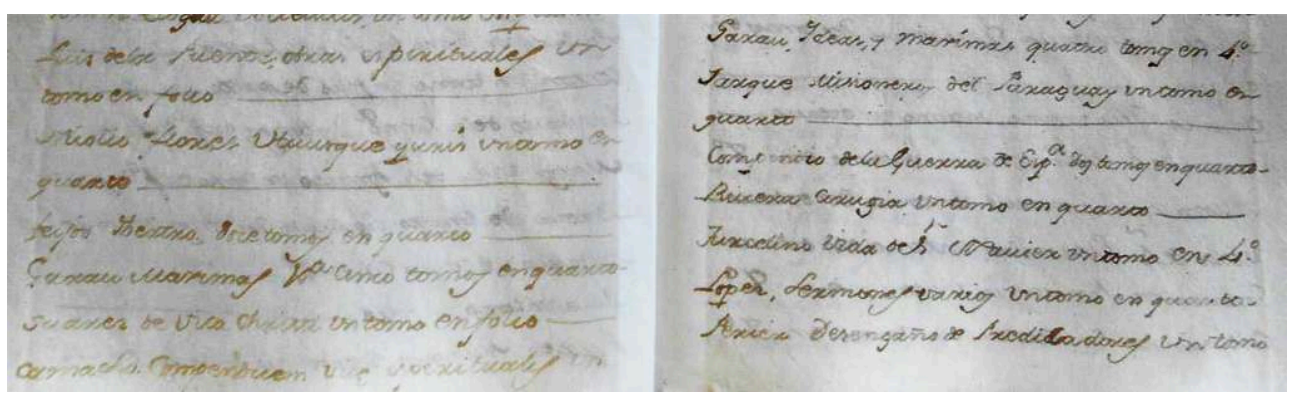

Imagen 10. Detalle de dos páginas contiguas del inventario de libros de la reducción de San Lorenzo (1768-1778), en las que se mencionan libros de Garau.

La obra de Garau ha sido considerada el centro de la literatura emblemática jesuítica española (Bernat Vistarini, 2000, p. 57). Este género consiste en composiciones multimediáticas que asocian un texto a una imagen simbólica. Implica la exposición de narraciones de contenido moral que acompañan un grabado alegórico (el emblema en sentido estricto) y pueden incluir una explicación conceptual de la alegoría. Según Antonio Bernet Vistarini, la emblemática específicamente jesuítica produce "un texto individual y casi íntimo", que pretende la interiorización del emblema (Bernat Vistarini, 2000, p. 58) y por eso se puede asociar a la compositio loci propia de los 
ejercicios espirituales (Chinchilla Pawling, 2004). No casualmente, en las bibliotecas misionales los libros de Garau aparecen a menudo ubicados en los estantes de la literatura espiritual. Esta temática fue ampliamente explotada por los jesuitas en la producción de textos en guaraní, como lo evidencian la traducción de la obra de Juan Eusebio Nieremberg, De la Diferencia entre lo temporal y lo eterno... (Gil, 2010) o la publicación de libros de ejercicios espirituales como Ara Poru aguı̌yey haba (Boidin, Cerno y Vega, en prensa).

En concreto, la Compañía de Jesús se valió de la literatura emblemática para su autopromoción en el marco de la propagatio fidei (Boer, Enenkel, y Melion, 2016; Dekoninck, 2008, 2014; Fabre, 2013). El ejemplo más significativo de una producción emblemática de este tipo es el libro Imago primi saeculi (1640), publicado por la provincia de Flandes-Bélgica en la conmemoración de los cien años de la fundación de la orden. Este libro incluye más de una centena de emblemas grabados en cartuchos que acompañaron la arquitectura efímera con la que los jesuitas celebraron este acontecimiento. El libro es un paradigma de la tradición emblemática de los colegios jesuíticos, donde los emblemas eran inventados y utilizados por los alumnos a partir de exposiciones temáticas llamadas affixiones. Ponían "en imágenes tanto las máximas de la sabiduría cristiana y antigua, como las verdades de la teología moral y especulativa" (Dekoninck, 2014, p. 71) y las trasladaban al lenguaje para develar su sentido, respetando las reglas lógicas de la escolástica y las oratorias de la retórica. El objetivo didáctico del género era explícito y de allí su utilidad en los colegios. La lectura, la interpretación escrita y oral y la composición de emblemas eran tareas obligadas para los alumnos. El género emblemático se caracterizaba también por una cierta creatividad lúdica basada en el principio de que lo útil debe agradar al alma y divertir. Asimismo, era parte del gusto barroco de la época, por cuanto los emblemas no debían ser completamente transparentes, sino descifrables a través de los rodeos del ingenio. En cualquier caso, el placer de estos "juegos del espíritu" conducía a la enseñanza de verdades de la fe, al comportamiento cristiano en el mundo y a la rectificación virtuosa y sabia del cuerpo (Dekoninck, 2014, p. 78).

El libro citado de Garau se divide en varias partes, cada una de las cuales contiene un grabado emblemático, una ficción con la narración de la ilustración y por último una máxima en la que se explica conceptualmente el conjunto. El fragmento transcripto en el documento (de manera no completamente exacta) ${ }^{23}$ corresponde al primer párrafo de la máxima. El grabado (véase Imagen 11) y la ficción consisten en la historia de un "rústico" a quien se hace creer que un espejo es una ventana de una casa en la que vive "un hombre encantado" que, con absoluto control de sí mismo, es capaz de imitar rápidamente todos los gestos y movimientos de quien lo observa. La máxima, cuyo subtítulo es "El Monarca de sí mismo" (Garau, 1690, pp. 436-460), utiliza el campo semántico de la política y las figuras retóricas propias del conceptismo para explicar, a partir de la ficción, que "gobernarse a sí mismo es ser rey", es decir, que el autocontrol del propio cuerpo siguiendo la razón constituye una virtud. Como lo ha indicado John T. Cull, el "subtexto político" de esta literatura es la autosuficiencia, entendida como sabiduría y felicidad y resultado de la razón y la fe en Dios (Cull, 2004, p. 254). El dominio que el alma ejerce se convierte así en una "monarquía" admirable que tiene como requisito evitar sucumbir a la "esclavitud" de las pasiones y los vicios. ${ }^{24}$ 


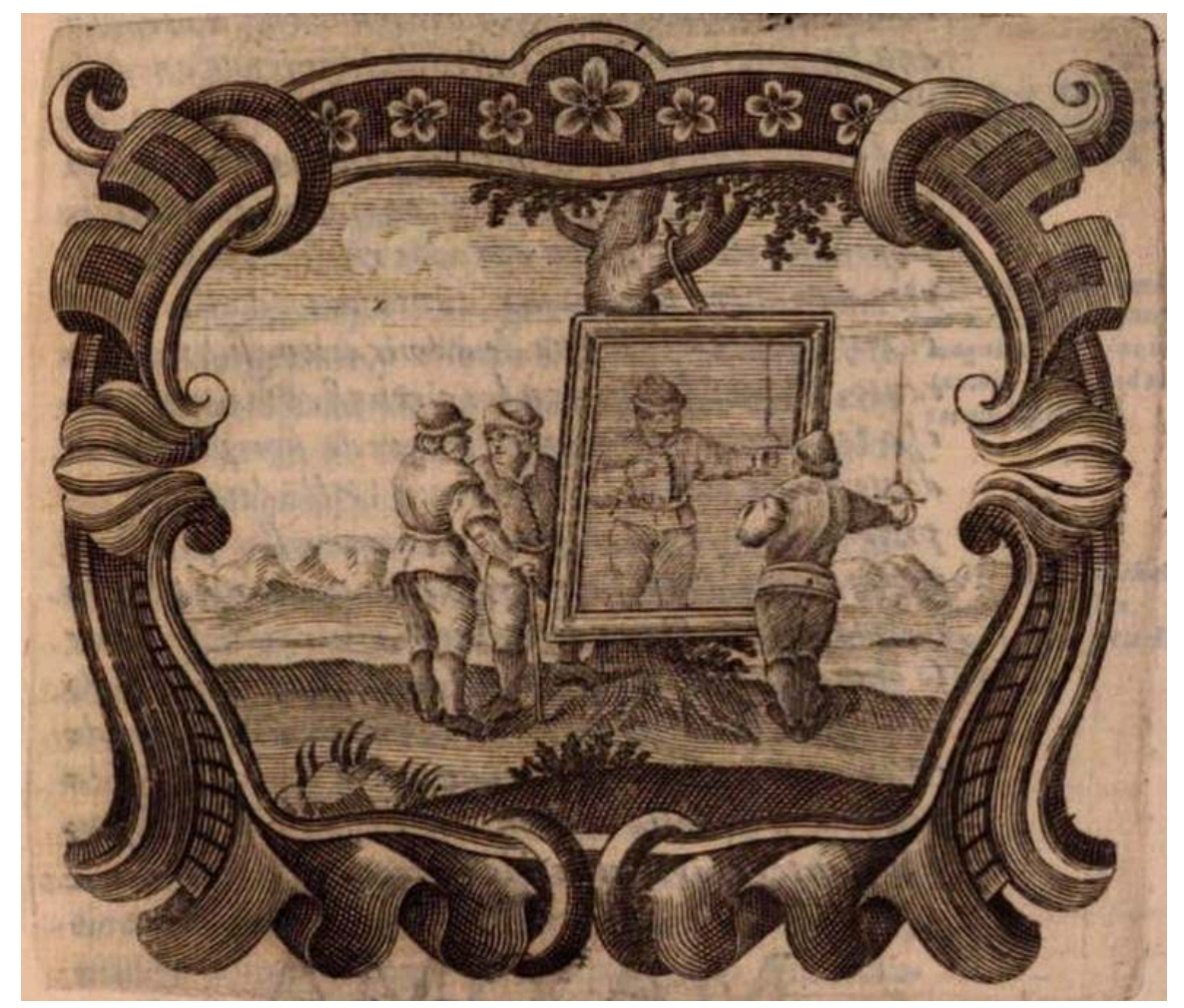

Imagen 11. Emblema que representa a un rústico observándose al espejo y creyendo que un hombre encantado repite sus gestos y movimientos (Garau, 1690, p. 435).

El papel en cuestión carece de indicios de haber ido acompañado de una imagen. Sin embargo, esta pudo efectivamente existir fuera del libro que la contiene y eventualmente ser expuesta en ocasiones especiales, como lo indica la investigación reciente sobre la emblemática en el mundo ibérico (Arellano y Pereira, 2010). La interpretación que este breve fragmento sugiere es que pudo tratarse de algún ejercicio de pedagogía moral ligado a esta tradición emblemática, llevado a cabo en algún colegio jesuítico de la región (como Asunción) o en las propias misiones de guaraníes.

\section{El fragmento en latín}

Et videntibus illis elevatus est et nubes suscepit eum ab oculis eorum. [Arriba: acta apostol.] Et const[it]uens / eum ad dexteram suam in celis [sic] supra omnem principatum, et potestatem, / et virtutem, et dominationem. S. Pablo a los Efecios. Principes Populorum congretati sunt cum Deo Abraham, quoniam Dii fortes terrae [Arriba: vehemenh (sic) elevati sunt].

Ascendet [sic] homo ad cor altum, et exaltabitr [sic] Deus.

Ascensiones in corde suo disposuit in loco, quem posuit.

El texto en latín, como el escrito en español, también comparte una de las caras del documento con expresiones en guaraní. Pero, a diferencia del anterior, no carece de referencias: "acta apostol." y "S. Pablo a los Efecios" remiten directamente a los libros bíblicos, lo que informa a su vez de la procedencia de todo el pasaje. En la modernidad temprana - hasta fines del siglo XVIII- la única versión de la Biblia autorizada por la Iglesia católica era la Vulgata en latín, específicamente la Vulgata Sixtina que había sido aprobada en el Concilio de Trento (1545-1563). En este sentido, la Biblia, que circuló ampliamente como libro durante los siglos XVII y XVIII, no estaba destinada a ser leída por los seglares sino por los miembros de la Iglesia, quienes eran capaces de reponer el 
sentido profético y alegórico establecido por la institución (Hansen, 2000; Julia, 2004, pp. 424-436). Para leer la Biblia, los seglares requerían una autorización especial de la jerarquía eclesiástica. En el Paraguay, las biblias estaban presentes en las bibliotecas de las misiones y a menudo existía una estantería específica para estos textos y sus comentarios. A pesar de esto, se trataría de una lectura casi enteramente dirigida a los jesuitas.

37 La producción textual de la época remitía constantemente a la Biblia, por lo tanto es posible que los fragmentos no hayan sido tomados directamente de las Escrituras. En cualquier caso, es evidente que constituyen una unidad y que quien los transcribió reconoció que se trataba del texto bíblico. Los fragmentos citados son cinco, tomados de un total de nueve versículos, no todos transcriptos de manera completa. Los dos primeros, los más extensos, derivan del Nuevo Testamento (Hechos 1:9 y Efesios 1:20-21), mientras que los tres restantes provienen del Antiguo, específicamente del Libro de los Salmos (Salmos 46:10-11; 63:7-8; 83:6-7). A diferencia de los primeros, estos últimos carecen de referencia que indique que son citas de los libros bíblicos.

Aunque es evidente que estos fragmentos son parte de una trama intertextual, la conexión entre los mismos es poco clara. El primero describe el ascenso de Jesucristo a los cielos y el segundo alude a su resurrección y ubicación a la derecha de Dios Padre. Este conjunto ascensión-resurrección es, sin duda, una unidad; podría incluso remitir al Credo, que era bien conocido por la población indígena de las misiones. La figura de Jesucristo también es mencionada en los fragmentos en guaraní. Pero la homogeneidad de las citas del Nuevo Testamento no se replica en el caso de los salmos, cuya conexión parece arbitraria y la manera en que están extractados los versículos, caprichosa. El primero menciona la congregación de los "príncipes de los pueblos" bajo el "Dios de Abraham" y ha sido visto por los exégetas católicos como una profecía de Jesucristo, pero los restantes están desconectados de cualquier posible interpretación crística. En cualquier caso, el conjunto de fragmentos bíblicos podría llegar a conformar una trama de reivindicación de Jesús y del poder del Dios cristiano, y eventualmente un conjunto de afirmaciones libremente relacionadas con el Juicio Final. Estas ideas parecen compatibles con el contenido de los textos en guaraní y no son extrañas en un conjunto textual con un carácter fuertemente performativo, en el que las postrimerías y los componentes apocalípticos ocupan un lugar destacado.

\section{Indicios y prácticas: cultura escrita y cultura religiosa en las misiones}

El previo análisis textual puede revelar el sentido de cada uno de los fragmentos, pero es la inclusión de todos ellos en un pequeño papel trilingüe lo que confiere al documento su carácter peculiar. No es posible la inducción de un significado global y, en consecuencia, el documento solo puede pensarse como indicio de prácticas históricas que tuvieron lugar en la misión o, eventualmente, en un colegio de la región. Independientemente de la oscuridad del sentido, las prácticas más obvias a las que podemos asociar el texto son la lectura y la escritura. Los fragmentos en español y en latín derivan de libros concretos. ${ }^{25} \mathrm{La}$ obra de Garau y la Vulgata estaban ampliamente distribuidas en las bibliotecas de las reducciones y de los colegios, que eran prácticamente los únicos espacios de la región que conservaban material bibliográfico (Vega, 2017). En las misiones, las bibliotecas se ubicaban en la residencia jesuítica, en 
los aposentos. Una o varias personas tomaron los libros de estos estantes y transcribieron los fragmentos pertinentes. Aunque la práctica de la cita pudo haber sido posterior a una lectura lineal, es más probable que haya derivado de una lectura fragmentaria y fraccionada, como era común frente a los libros espirituales en la época (González Sánchez, 2003) y sigue siéndolo hoy para el caso de los textos bíblicos.

40 Pero la literatura emblemática, presente a través de la cita de Garau, enlaza esta práctica de lectura con el desarrollo de la cultura visual y simbólica orientada pedagógicamente. En efecto, aunque los libros de emblemas contenían texto, este no estaba desconectado de las imágenes, sino que servía como un complemento de las mismas. En este sentido, es posible que la cita de Garau haya acompañado alguna forma de circulación del grabado de su libro o bien que esta imagen haya servido de inspiración primaria para transcribir el fragmento del texto. La combinación del registro textual y visual (performativo) se constata en diversos ámbitos de la misión. La investigación sobre la cultura escrita ha revelado el uso sistemático de imágenes acompañando sermones y exempla en textos específicos como los sermones de Nicolás Yapuguay o la versión guaraní del famoso libro de Nieremberg (Brignon, 2016, 2017; Wilde, 2019).

41 En este mundo de registros intermediarios, adquiere sentido lo que se llamó escritura expuesta o escritura para ser vista, de la que se conservan numerosos ejemplos en las misiones y fuera de ellas. Por ejemplo, se constata la existencia de símbolos de Cristo y María en muros de las iglesias misionales. En este caso no se trataría de textos propiamente dichos sino de ideogramas, cuyo significado se infiere sin la ayuda de la lengua pero que podrían implicar todo un programa de exposición gráfica (Petrucci, 2003, pp. 11-25). Crónicas como las de José Cardiel (1704-1782) o José Manuel Peramás (1732-1793) también refieren la realización de danzas y representaciones que dibujan letras con el nombre de la Virgen, que asumimos que podía ser reconocido visualmente por la población indígena (Furlong, 1953, p. 166; Peramás, 1791, p. 86). El sentido de estas escrituras expuestas era performativo y rectificador del comportamiento puesto que, según muestra Dekoninck, los jesuitas entendían la formación como una verdadera Bildung, es decir, una resultante de la fabricación de la imagen del buen cristiano: "los jesuitas no conciben su programa escolar sino como una 'formación' de las almas a imagen de los ejemplos que les son dados como modelos" (Dekoninck, 2014, p. 81). La representación dramática, el teatro, fue una prolongación natural de dicha formación, a menudo cargada de alegorías, de la cual se conservan evidencias en el ámbito misional y que, como ya se ha indicado, comparten por lo menos en ocasiones el carácter trilingüe del documento analizado.

Las diversas modalidades combinatorias de imagen y texto se orientan a constituir una memoria misional ligada a las buenas costumbres cristianas, cuya continuidad en el tiempo debe actualizarse en cada ocasión. Como lo han indicado diversos trabajos para el ámbito colonial, la conjunción imagen-texto resulta eficaz para la trasmisión de conocimientos ligados al orden cristiano, que frecuentemente se sirven de mecanismos y soportes preexistentes (Farago, 1995; Rappaport y Cummins, 2011). En un interesante trabajo de comparación de sistemas de memoria, Carlo Severi muestra que las diversas artes de la memoria amerindias combinan, a nivel de los "procesos mentales", un principio de saliencia visual y uno de orden lógico, que en la práctica ritual demuestra gran eficacia. Las artes de la memoria del Renacimiento combinan estos registros a su 
modo, logrando efectos parecidos (Severi, 2010). Podría decirse que dichos "procesos mentales" también se encuentran presentes en la literatura emblemática.

Fue común que los jesuitas expandieran sus estrategias urbanas hacia los espacios misioneros y que eventualmente recrearan géneros textuales y performativos canónicos para adaptarlos a circunstancias nuevas. En este sentido, el documento en cuestión puede bien estar señalando la existencia de un género textual sui géneris de carácter performativo, ligado tanto a la pedagogía moral como a la devoción. En Paraquaria, dichas prácticas pudieron desarrollarse o bien en el ámbito de las congregaciones religiosas (misioneras o urbanas) o bien en los colegios situados en las ciudades de la región. Podría decirse que la pista emblemática del documento nos llevaría por el segundo camino y la pista lingüístico-guaraní por el primero. No obstante, cabe preguntarse si no estamos frente a un género híbrido, desarrollado en o para la misión, que combinaba la tradición emblemática, pedagógica y moral de los colegios con recursos devocionales propios del ámbito reduccional. El carácter general del texto es más bien solemne, lo que lo alejaría de la pedagogía didáctica y de los “juegos espirituales” típicos de la emblemática jesuítica. En cualquier caso, la combinación de géneros y la orientación solemne de la práctica textual devocional pudo responder a un motivo eminentemente pragmático, como se constata también en el ámbito visual y sonoro de las misiones (Escobar, 2004; Illari, 2005; Plá, 1975; Wilde, 2015).

Además de la lectura y la performance visual, el documento revela otra práctica, igualmente obvia: la escritura. En primer lugar, manifiesta que también en las misiones o en los colegios se leía "con la pluma en la mano". El o los lectores trasladaron los pasajes de interés del libro impreso a un pequeño papel. Como lo resaltó Chartier, la cultura impresa habilitó usos novedosos de la escritura manuscrita (2016, pp. 15-23). Aunque la comparación puede parecer excesiva, la práctica de lectura-escritura que el documento trilingüe revela guarda un parecido morfológico con la lectura "pluma en mano" de los humanistas, en la que la escritura era una forma de lectura, "un homenaje letra por letra al poder del original" (Grafton. 2004, pp. 363-364); y también con la producción de commonplace books identificada por la historiografía anglosajona (un ejemplo concreto en Steedman, 2007, pp. 47-65), que consistía en la transcripción heterogénea y desordenada de pasajes literales de libros, como una manera de "conservar" la lectura. En la tradición retórica, tan presente entre los jesuitas, esta práctica podía tener sentido en el marco de la predicación. En efecto, una escritura asociada a la lectura era parte de las artes de memoria enseñadas en los colegios jesuíticos, técnicas mnemotécnicas que implicaban la extracción y retención de lugares comunes. Incluso era frecuente colectar "conceptos predicables" de la Biblia en pequeños cuadernillos y utilizarlos posteriormente en los sermones (Hansen, 2000). Toda la materia de la predicación católica posterior al Concilio de Trento aparecía codificada en este tipo de tópicos, disponibles en la memoria del orador.

En cualquier caso, los usos y funciones de estas prácticas de escritura podían ser variados: además de a la predicación, podían servir también al estudio, al cultivo espiritual o a artes mnemotécnicas. En conjunto esto nos remite a una praxis religiosa menos evidente. ¿Praxis de los jesuitas o, tal vez, de los indios? La mayoría de los indígenas letrados de las misiones podía vocalizar o entender los sonidos del español y el latín del documento, pero no necesariamente comprenderlos. Unos pocos parecen haber alcanzado el manejo con soltura del latín, por ejemplo, Nicolás Yapuguay, quien 
cita fragmentos bíblicos en sus libros, ciertamente escritos con supervisión jesuítica. Al mismo tiempo, los jesuitas solo utilizaban el guaraní para comunicarse con los indios y no para la lectura o la devoción personales. La combinación de lenguas complejiza entonces sobremanera la interpretación de la "autoría" del documento. Sin embargo, el estudio de la cultura escrita de las misiones, en especial aquella en lengua guaraní, ha demostrado que en cuanto al proceso de producción primaba la colaboración entre varios indígenas y varios jesuitas (Brignon, 2018). En efecto, los sacerdotes o los indios podían actuar como escritores, transcriptores, copistas, informantes y correctores en distintas combinaciones. Así, la existencia de texto en español y en latín sugiere la autoría, la supervisión o la presencia jesuíticas, pero las expresiones en guaraní indican que los indios o los criollos guaraní-parlantes estaban presentes ya sea como productores o como receptores.

Como se lo ha indicado, el contenido del documento habilita que pudiera servir a la predicación, a la devoción personal o a la pedagogía moral. En las misiones y en las áreas rurales de Asunción y Corrientes los jesuitas predicaban en guaraní. Algunos indios letrados de las reducciones también pronunciaban sermones. El contenido textual del documento parece compatible con una pragmática oral de predicación. Se ha sugerido incluso que la obra emblemática de Garau, que aparece citada, contiene en verdad "sermones velados" (Cull, 2004, p. 237), lo que reforzaría esta idea. El uso de fragmentos bíblicos también estaría en consonancia con las definiciones del catolicismo, que restringía la enseñanza del contenido de las Escrituras a la oralidad predicable (Hansen, 2000). Los textos son asimismo compatibles con una tradicional devoción ignaciana, de la que participaban los jesuitas en todo el orbe -especialmente a través de los ejercicios espirituales-. La literatura emblemática o fragmentos de la Biblia podían tener un sentido como lecturas espirituales en este marco devoto, o, como ha sido señalado por los estudios especializados, como el ejercicio de la moralidad ligado simultáneamente al uso de la razón y de los sentidos, en concreto el de la vista. Recientemente se ha revelado que esta praxis devocional, en principio solo asociada a los jesuitas, pudo haberse extendido entre un sector de la población indígena a través de la lectura (Boidin, Cerno y Vega, en prensa). Aunque la realización de ejercicios espirituales y la predicación son prácticas diferenciadas, los mismos materiales podían utilizarse en uno y otro caso, y el documento analizado parece inscribirse en este marco ambivalente. Su inserción en el programa pedagógico jesuítico abre incluso un tercer espacio posible de uso, ligado a una didáctica moral de profundo arraigo entre los misioneros.

Más allá del carácter evidentemente performativo de estos textos, el documento puede ser leído desde otro plano. En efecto, los dobleces del papel que hemos identificado dan cuenta de que fue plegado para transportarse, guardarse o conservarse, quizás de forma íntima. Tanto los jesuitas como los guaraníes podían utilizar pequeños papeles de este tipo para diversas finalidades. Por ejemplo, conocemos entre los misioneros la práctica de anotar observaciones de carácter lingüístico sobre el guaraní en pequeños papeles. En una carta anua temprana, el jesuita Diego de Torres (1551-1638) menciona "papelillos de la lengua que había escrito" (Leonhardt, 1927, p. 177). En otros contextos, se han registrado usos devocionales y en algunos casos mágicos del papel por parte de los jesuitas, como es el caso de los recortes de cartas y firmas por Francisco Javier (Morales, 2011, p. 41). Más significativamente, hay testimonios del uso que la población indígena podía dar a estos objetos. Sabemos que los miembros de las congregaciones (o cofradías) recibían pequeños papeles que daban cuenta de su "esclavitud" a la figura de 
su devoción. En las misiones existían dos congregaciones con diferencias etarias, la de San Miguel Arcángel para los jóvenes y la de la Virgen María para adultos (Martini, 1992; Takeda, 2017; Wilde, 2017). Los integrantes de estas instituciones conformaban el sector más devoto y cercano a los jesuitas dentro de las reducciones. La estima que tenían por papeles escritos relacionados con su actividad devota era muy grande, e incluso solían llevarlos "colgados en el cuello (sobre el pecho)", según informa una carta anua de fines del siglo XVII (Neumann, 2015, p. 87). Otro cronista jesuita da cuenta de que muchos indios podían curarse de sus enfermedades "con solo aplicarles un papelito" escrito por el misionero que dijera "Sancte Francisce Xavier, ora pro nobis" (Neumann, 2015, p. 88). Como analiza Neumann, parece que aquí estamos frente a un fenómeno de apropiación mágica del escrito - a la manera de un amuleto o talismán- (2015, pp. 86-89), un fenómeno por otro lado bastante extendido en la modernidad temprana (Bouza, 2001; Chartier, 2016, pp. 29-31). Los pliegues y dobleces que dan cuenta de la apropiación del documento por lo menos sugieren la posibilidad de un uso de este tipo.

Los pliegues y dobleces refuerzan las dudas sobre la autoría de este documento particular. Aunque se ha identificado el uso de pequeños papeles por algunos jesuitas con finalidades lingüísticas, no resulta claro por qué un religioso mantendría en su poder breves apuntes devocionales pudiendo acceder directamente a los textos citados en su aposento. El breve fragmento en latín podría sugerir un manejo al menos limitado de la lengua latina, como tal vez pudo alcanzar un indio letrado. A su vez, el contenido y los rasgos de los fragmentos en las tres lenguas se ajustan a los que conocemos como "auxilios de memoria" para la oración o la recitación. Los jesuitas no necesitaban guardar un documento con estas características de manera "privada", casi como si se tratara de una reliquia. Esto refuerza la hipótesis de que el documento haya podido ser producido o al menos utilizado por un miembro de las congregaciones religiosas, pues en estas instituciones dedicadas a la devoción existían los medios materiales y culturales para la escritura -tinta, pluma, papel-y la lectura.

Llegados a este punto podemos decir que nos encontramos frente a un pequeño documento que se inscribe de manera problemática en la cultura escrita conocida de Paraquaria. Pero su carácter trilingüe, a pesar de su rareza intrínseca, confirma esta pertenencia. Su finalidad performativa es evidente y el contenido de los fragmentos, oscuros en su interrelación, coincide con esta idea. Los dobleces y pliegues dan cuenta de una apropiación peculiar, de una devoción quizás íntima y cercana a la recepción simbólico-mágica de la escritura, por otro lado no incompatible con su uso en el marco de la oralidad.

Desde una perspectiva general, la cultura escrita misional, como otros dispositivos y tecnologías de gobierno, respondía a la finalidad de producir un cuerpo, un comportamiento y una persona cristianos. Las distinciones rígidas (entre jesuitas e indígenas, entre predicación y devoción, entre una performance "pública" y una apropiación íntima, entre lo espiritual y lo no espiritual) no resultan útiles para comprender la especificidad del proceso cultural misional (Wilde y Vega, 2019). ${ }^{26}$ 


\section{El documento en la trama intertextual. Criterios para un inventario}

51 Nuestro análisis indica que estamos frente a un documento excepcional, que no encaja completamente en ninguna de las clasificaciones preestablecidas. Dado que el lugar que positivamente ocupa en un posible inventario de la cultura escrita de las misiones no está claro, conviene en esta etapa de la investigación delimitar, de manera provisoria y esquemática, los criterios generales de clasificación de dicha cultura escrita para una estadística que realizaremos en el futuro. ${ }^{27} \mathrm{La}$ rareza del documento estimula a considerar el entramado textual en su conjunto, con el objetivo de completar el panorama. Esto constituye un dilema nodal para el estudio integral que nos proponemos. Cabe destacar que el inventario de los materiales efectivamente localizados (en archivos y bibliotecas) no agota la totalidad de la cultura escrita de las misiones. Una clasificación completa debe incluir documentos referidos por diferentes fuentes (especialmente en crónicas e inventarios de bibliotecas) aunque no hayan sido localizados físicamente en ningún repositorio. ${ }^{28}$ Por esas fuentes sabemos de la difusión de documentos trilingües como el que aquí nos ocupa y de la posible circulación de los mismos, tanto entre misiones específicas como entre diferentes conjuntos misionales de la orden jesuita..$^{29}$ Los criterios que este documento nos invita a explorar son los siguientes:

52 1. Lengua. Un inventario global de la cultura escrita misional debe considerar todos los textos producidos y circulantes en ese ámbito, no exclusivamente aquellos en la lengua general. Aunque mayoritaria, esta no fue la única lengua hablada en estos ámbitos. El carácter trilingüe del documento constituye un dato importante que invita a reflexionar sobre las tendencias que ha seguido la investigación en los últimos años. Si bien los textos trilingües fueron ocasionalmente producidos en los ámbitos misionales con fines litúrgicos, las características de este en particular son extrañas. Cada uno de los fragmentos parece tener una lógica propia, sin exhibir conexiones evidentes entre sí, dificultando una comprensión general del texto y sus posibles funciones.

53 2. Lugar. Un inventario general debe incluir el circuito ampliado de producción y recepción de textos orientados a la actividad misionera, tanto aquellos elaborados dentro de las reducciones como fuera de ellas. En la época de nuestro documento hemos identificado la existencia de una constelación de textos devocionales que expresan el grado máximo de desarrollo de las capacidades de traducción de conceptos teológicos a la lengua guaraní. Los lugares de producción (escrita e impresa) de estos textos se ubican principalmente dentro de las misiones, pero también fuera de ellas, en el polo editorial madrileño. Dentro de las misiones, existen usinas específicas de producción textual que conforman una constelación de pueblos privilegiados. El documento aquí considerado pudo haber sido producido en estas usinas, pero no deberíamos descartar que haya sido elaborado en un colegio jesuítico de la región, como Asunción o Corrientes.

54 3. Autoría. Aunque este aspecto no es siempre relevante, aquí resulta de interés para la comprensión de la cultura escrita de las misiones. Parece razonable atribuir el documento en cuestión a un solo autor. Es factible que fuera escrito por un indio de la élite misionera, pero no podemos afirmarlo taxativamente. La creciente participación de la élite indígena en la producción de documentos -incluso los más sofisticados desde el punto de vista teológico- es un hecho constatado para la época. A pesar de 
esto, la caligrafía del texto no tiene la perfección constatable en la mayor parte de los documentos de mano indígena. En cuanto al contenido, no parece señalar de manera clara un productor-receptor sacerdote. Este punto permanece entonces como un enigma.

4. Formato (impreso o manuscrito). El hecho de tratarse de un documento trilingüe manuscrito, dentro de un corpus mayor donde esta característica generalmente corresponde a textos impresos, resulta un dato de interés. El carácter inmediato del manuscrito señala que el trilingüismo tal vez haya sido una atribución valorada y hasta requerida en ciertos ámbitos de desenvolvimiento de la actividad escritural misionera.

5. Género textual. El documento parece definir una especie textual única que no entra en ninguna clasificación preestablecida. Ni el contenido del texto ni sus aspectos materiales autorizan inscribirlo en los géneros conocidos. Su posible vinculación con técnicas de memoria asociadas a la emblemática jesuítica constituye una pista emergente que requiere de mayor profundización. Los aspectos relacionados con la conservación del papel en un legajo misceláneo del AGN tampoco indican ninguna asociación posible con otros documentos.

6. Materialidad. Este documento, como la mayor parte de los escritos, tiene como soporte material el papel. Pero en las misiones también existió escritura inscripta en madera, piedra, barro o cuero, lo que en buena medida condicionó los efectos performativos del texto (por ejemplo, la posibilidad de transformarse en escritura expuesta). ${ }^{30}$ Las dimensiones y la pervivencia de marcas de pliegue en el papel indican además que se trató de un documento para ser transportado o eventualmente guardado, y da indicios de un cierto uso ligado a la intimidad de la lectura en circunstancias que desconocemos. Este rasgo es común a otros textos de las misiones, aunque rara vez de contenido religioso.

58 7. Paratextualidad. Generalmente asociados a su recepción en el circuito misional, los textos incluyen variaciones tipográficas (en el caso de un mismo ejemplar impreso), anotaciones, marginalia manuscrita, dibujos, garabatos, etc. El documento en cuestión contiene marcas cuyo sentido por ahora no puede elucidarse, como la inclusión de la leyenda "Paraq". La contramarca de la filigrana es un elemento material que tampoco brinda pistas.

8. Original y copia. Una cuestión poco discutida en la clasificación documental consiste en indagar sobre la naturaleza del documento en tanto original y copia. En efecto, hay documentos del ámbito reduccional -como los administrativos, pero no exclusivamente- que son sistemáticamente copiados y traducidos, dos prácticas específicas de mediación dentro de la cultura escrita de las misiones. Muchos documentos existentes fueron copias que pasaron a conservarse en diferentes archivos, dentro de las mismas misiones o fuera de ellas. Es indiscutible el carácter original del documento analizado, aserción que encuentra fundamento en el aura del mismo, restringido a un ámbito de devoción personal.

\section{Reflexiones finales y preguntas abiertas}

Entre fines del siglo XVII y la expulsión (1767-1768), jesuitas y/o indígenas letrados, en las misiones o en los colegios del Paraguay, produjeron un enigmático y minúsculo documento escrito en tres idiomas. Este contiene fragmentos bíblicos, una cita de una 
máxima de la literatura emblemática jesuítica e invocaciones u oraciones en la lengua general. El sentido del conjunto textual es oscuro, pero el carácter performativo y devoto del papel es innegable. Los pliegues materiales del soporte indican por su parte que fue guardado o atesorado, tal vez para ser leído en la intimidad. Se trata de un documento nunca antes comentado en la investigación especializada y al mismo tiempo irreductible a cualquier intento de clasificación. En este sentido, es un documento que solo ahora ha sido "desclasificado".

61 Al mismo tiempo, esta fuente señala la necesidad y urgencia de avanzar en la confección de un inventario y una tipología de la totalidad del corpus de la cultura escrita de las misiones. Su rareza intrínseca estimula la elaboración de clasificaciones refinadas que puedan captar el carácter específico y las peculiaridades de esta cultura. Los contenidos, formatos y funciones de la cultura escrita son muy diversos, incluyendo desde los estrictamente lingüísticos (vocabularios, tesoros y artes de la lengua), hasta los religiosos (sermones, catecismos, rituales, etc.), políticos (actas de cabildos, cartas entre autoridades, etc.) y económicos (inventarios, libros contables, etc.). No se ha desarrollado hasta el momento una tipología exhaustiva y completa, salvo por algunos intentos parciales (Boidin, 2017; Melià, 1992; Neumann, 2015; Wilde, 2014). Tampoco existe un programa sistemático de digitalización de estos materiales, que permita un acercamiento a sus contenidos específicos y su posible circulación regional, continental y atlántica.

62 El documento analizado añade variedad a un panorama ya de por sí complejo y nos invita a expandir la exploración de la cultura escrita de las misiones más allá de la dimensión textual en, al menos, dos sentidos. El primero consiste en el análisis de la combinación de formas escritas y visuales dentro de los documentos. El segundo implica abordar la dimensión performativa de estos materiales como instancia particular de recepción. La consideración de estos elementos de la materialidad de la cultura escrita lleva a indagar, en las adaptaciones locales, el desenvolvimiento de una cultura gráfica misional (que incluye también a la cartografía) y más ampliamente la configuración de una "memoria" misional que se expresó en representaciones singulares del espacio, el tiempo, el cuerpo y la subjetividad. La cultura escrita misional constituye, en definitiva, un elemento de la materialidad misional (puede decirse la sensorialidad misional), que debe ser integrado al análisis de formas sui géneris de percepción del tiempo y el espacio en contextos de interacción de la América colonial.

\section{Transcripción del documento “Dominio despotico con esclavos, politico con iguales...", número $106^{31}$}

Primera cara

Dominio despotico con esclavos, politico con iguales, y con subditos real / despoticamente manda el alma al cuerpo como a esclavo, politicamente el / entendimiento a la voluntad como a compañera, y assi armada / la voluntad impera como reyna a la parte concupiscible, e irascible, / y demas paciones inferiores como a subditos.

Ma 


\begin{tabular}{|c|c|}
\hline Angeles ǐbapegua ${ }^{\text {ra }}$ pegueyı̆ co arap̌pe & Mburubicha ap̌reỹ \\
\hline Jesus mbaeete hara & hae Aba pǐcirohara \\
\hline mborahei porapīpe & Teô imboaguı̌yepı̌rey. \\
\hline
\end{tabular}

Ha Jesus cheyara. curiautamo S. Lorenzo igua. [Arriba: A] cheropa. curiautamo Aba, hae / cuna pabengatu nderuguĭ marangatu pǐpe nderembiyoguacue co [Arriba: hae pota Jesus che] arete gua / zupīpe ndehaguĭqua ĭbape rae. Angeles ñabebe ndemboyerobiahaguamari. / Ayete cheraĭ reta Nande ruı̆pı̆cue Adan hae Eva. $\mathrm{M}^{\mathrm{a}}$. Peñeinanga cheraǐ / reta che raš reta ramo. peñemomburu, pequĭ rey ngatu anga. iba[g]a re / peña haguamari. Haete peñemocanionde catu range peporoabŭ quǐbone / mbaepe peiapone che peeme imboyequahaguamari aycotebe tupa gracia / hebe Penemomburu catu anga ỉbape pequebo, Haete mamorupipa / peyaupine che peeme imboyequaahaguamari aycotebe tupa gracia

71 Tercera cara, anverso de la primera Ah cheraĭ reta curiauramo co tupa. rerobiaha. tupa. N.Y ĭt mamo paperupi / recoha ace pra rehe oyequahacatu anga rae, mamopaberupi, ndeprguata / ha rupi nde mongeta Hagua.

\section{Traducción de los fragmentos en guaraní y latín del documento 33}

\section{Primera cara (fragmentos en guaraní)}

\begin{tabular}{|l|l|}
\hline Ángeles del cielo bajad en este día & Eterno Todopoderoso \\
\hline Jesús generoso & salvador de los hombres \\
\hline Cantad en alabanza & de quien derrota eternamente a la muerte \\
\hline
\end{tabular}




\section{Segunda cara (latín y guaraní)}

Y viéndolo ellos se fue elevando y le recibió una nube que le ocultó a sus ojos [Arriba: Hechos de los Apóstoles] [Hechos 1:9]. Y colocándolo / a él su derecha en los cielos sobre todo principado, y potestad, y virtud, y dominación. San Pablo a los Efesios [Efesios 1:20-21].

Los Príncipes de los Pueblos se congregaron con el Dios de Abrahám, porque los Dioses fuertes de la tierra en gran manera fueron ensalzados [Salmos 46:10].

Ascenderá el hombre a lo profundo del corazón, y será Dios ensalzado [Salmos 63:7-8].

Subidas dispuso en su corazón en el lugar que asentó [Salmos 83:6-7].

Oh Jesús mi señor. Ojalá me pierda de los sanlorenzanos. Ojalá todos los hombres y / mujeres por tu sangre santa en estas Pascuas (es deseo de mi Jesús) / vayan al cielo detrás de ti, volando como ángeles para adorarte. / Mis hijos, Adán y Eva son en verdad nuestros santos antepasados. ¡Ea, mis hijos / e hijas, ejercitaos para alcanzar el cielo, / esforzaos, daos maña / en todas las actividades que vayáis a hacer! Para que os explique a vosotros, necesitaría de la gracia de Dios. / ¡Ejercitaos para alcanzar el cielo! Pero para todas las cosas / que yo os explicaría, necesitaría de la gracia de Dios.

Tercera cara, anverso de la primera (guaraní)

¡Ah, mis hijos, sed fieles! Dios Nuestro Señor con cuidado, no importa dónde estemos, / se manifiesta en nuestro corazón, como bien se sabe se presenta por todas partes, por los pasos de tus pies, / para hablarte.

\section{BIBLIOGRAFÍA}

Arellano, I., y Pereira, A. M. (2010). Emblemática y religión en la península ibérica. Madrid: Universidad de Navarra/Iberoamericana/Vervuert.

Austin, S. M. (2015). Guaraní kinship and the encomienda community in colonial Paraguay, sixteenth and early seventeenth centuries. Colonial Latin American Review, 24, 545-571.

Bernat Vistarini, A. (2000). La emblemática de los jesuitas en España: Los libros de Lorenzo Ortiz y Francisco Garau. En R. Zafra Molina y J. J. Azanza López (Eds.), Emblemata aurea: la emblemática en el arte y la literatura del siglo de oro, (pp. 57-68). Madrid: Akal.

Bernat Vistarini, A. (2002). Emblema in fabula: El sabio instruido de la naturaleza, de Francisco Garau. En A. Bernat Vistarini y J. T. Cull (Eds.), Los días del Alción: emblemas, literatura y arte del Siglo de Oro, (pp. 83-92). Universitat de les Illes Balears, Servicio de Publicaciones.

Bernat Vistarini, A., y Cull, J. T. (2017). Insights on Original Narrative Fiction in the Political Emblematics of Diego de Saavedra Fajardo, Andrés Mendo, and Francisco Garau. Análisis. Revista de investigación filosófica, 4 (2), 297-320.

Boer, W. de, Enenkel, K., y Melion, W. (Eds.). (2016). Jesuit image theory. Leiden: Brill. 
Boidin, C. (2017). Mots guarani du pouvoir, pouvoir des mots guarani. Essai d'anthropologie historique et linguistique (XIX-XVI et XVI-XIX) (Thèse d'habilitation). Université Sorbonne Nouvelle.

Boidin, C., Cerno, L., y Vega, F. R. (en prensa). “This Book is Your Book”. Jesuit Editorial Policy and Individual Indigenous Reading (Paraguay, 18th Century). Etnohistory.

Bouza, F. (1992). Del escribano a la biblioteca. La civilización escrita europea en la Alta Edad Moderna (siglos XV-XVII). Madrid: Síntesis.

Bouza, F. (2001). Corre manuscrito. Una historia cultural del Siglo de Oro. Madrid: Marcial Pons Historia.

Brignon, T. (2016). Mba'e mỹmba pype : "par le biais des animaux". La traduction en guarani d'un bestiaire salutaire : l'édition missionnaire de la Diferencia entre lo temporal y eterno de Juan Eusebio Nieremberg (Loreto, 1705). Paris: Institut des Hautes Études de l'Amérique Latine (IHEAL), Université Paris III Sorbonne Nouvelle.

Brignon, T. (2017). Un traduteur exemplaire. Le cacique Nicolás Yapuguay et ses exempla en langue guarani (missions jésuites du Paraguay, 1724-1727) (Mémoire de Master 2 recherche. Études hispanophones). Lyon: Université de Lyon, ENS de Lyon.

Brignon, T. (2018). Du copiste invisible à l'auteur de premier ordre. Le traduction collaborative de textes religieux en guarani dans les réductions jésuites du Paraguay. Sociocriticism, 33, 299-338.

Caballos Piñero, A. (2013). Etnografía guaraní en el Tesoro de Ruiz de Montoya. Asunción: CEPAG.

Castillo Gómez, A. (Ed.). (2002). Historia de la cultura escrita. Del Próximo Oriente Antiguo a la sociedad informatizada. Gijón: Trea.

Castillo Gómez, A. (2003). Historia de la cultura escrita: ideas para el debate. Revista brasileira de história da educação, 5, 93-124.

Castillo Gómez, A. (2006). Entre la pluma y la pared. Una historia social de la escritura en los siglos de oro. Madrid: Akal.

Clossey, L. (2008). Salvation and Globalization in the Early Jesuit Missions. New York: Cambridge University Press.

Cerno, L., y Obermeier, F. (2013). Nuevos aportes de la lingüística para la investigación de documentos en guaraní de la época colonial (Siglo XVIII). Folia Histórica del Nordeste, 21, 33-56.

Certeau, M. de. (2006). La escritura de la historia. México: Universidad Iberoamericana.

Chamorro, G. (2009). Decir el cuerpo: historia y etnografía del cuerpo en los pueblos guaraní. Asunción: Editorial Tiempo de Historia.

Chartier, R. (1992). El mundo como representación: estudios sobre historia cultural. Barcelona: Gedisa.

Chartier, R. (1996). Escribir las prácticas: Foucault, de Certeau, Marin. Buenos Aires: Manantial.

Chartier, R. (2016). La mano del autor y el espíritu del impresor. Siglos XVI-XVIII. Buenos Aires: Katz Editores.

Chinchilla Pawling, P. (2004). De la Compositio Loci a la República de las Letras. Predicación jesuita en el siglo XVII novohispano. México: Universidad Iberoamericana.

Couchonnal, A., y Wilde, G. (2014). De la política de la lengua a la lengua de la política. Cartas guaraníes en la transición de la colonia a la era independiente. Corpus. Archivos virtuales de la alteridad americana, 4 (1). 
Cull, J. T. (2004). The Baroque at Play, Homiletic and Pedagogical Emblems in Francisco Garau and Other Spanish Golden Age Preachers. En F. A. De Armas (Ed.), Writing for the Eyes in the Spanish Golden Age, (pp. 237-256). Bucknell University Press.

Cull, J. T., y Bernat Vistarini, A. (2010). Reason of State and Heresy in the Works of Francisco Garau. En P. F. Campa y P. M. Daly (Eds.), Emblematic Images \& Religious Texts. Studies in Honor of G. Richard Dimler (pp. 229-252). Philadelphia: Saint Joseph's University Press.

Dekoninck, R. (2008). Imaginar la ciencia: la cultura emblemática jesuita entre ars rhetorica y scientia imaginum. En P. Chinchilla y A. Romano (Eds.), Escrituras de la modernidad. Los jesuitas entre cultura retórica y cultura científica, (pp. 143-157).México: Universidad Iberoamericana.

Dekoninck, R. (2014). Conformarare mores. La cultura emblemática en la pedagogía jesuita. En P. Chinchilla, A. Mendiola, y M. Morales (Eds.), Del Ars Historica a la Monumenta historica. La historia restaurada, (pp. 67-93). México: Pontificia Universidad Javeriana/Universidad Iberoamericana Puebla/Universidad Iberoamericana Ciudad de México.

Dreidemie, O. J. (1937). Los orígenes del teatro en las regiones del Río de la Plata. Estudios, LVII, 61-80.

Escobar, T. (2004). El barroco en el mundo guaraní: colección Latourrette Bó. Asunción, Paraguay: Ediciones Fotosíntesis.

Estenssoro, J. C. (2015). Las vías indígenas de la occidentalización. Lenguas generales y lenguas maternas en el ámbito colonial americano (1492-1650). Mélanges de la Casa de Velázquez. Nouvelle série (45-1), 15-36.

Estenssoro, J. C., e Itier, C. (2015). Présentation (dossier Langues indiennes et empire dans l’Amérique du Sud coloniale). Mélanges de la Casa de Velázquez. Nouvelle série, (45-1), 9-14.

Fabre, P.-A. (2013). Ignacio de Loyola. El lugar de la imagen. El problema de la composición de lugar en las prácticas espirituales y artísticas jesuitas en la segunda mitad del siglo XVI. México: Universidad Iberoamericana.

Farago, C. J. (1995). Reframing the Renaissance: Visual Culture in Europe and Latin America, 1450-1650. Yale: Yale University Press.

Fraschini, A. E. (Ed.). (2005). Index librorum Bibliothecae Collegii Maximi Cordubensis Societatis Jesu anno 1757: edición crítica, filológica y biobibliográfica (Vol. 1). Córdoba: Universidad Nacional de Córdoba.

Friedrich, M. (2008). Government and Information-Management in Early Modern Europe: The Case of the Society of Jesus. Journal of Early Modern History, 12, 539-563.

Furlong, G. (Ed.). (1953). José Cardiel, S. J. y su Carta-Relación (1747). Buenos Aires: Librería del Plata.

Furlong, G. (1962). Misiones y sus pueblos guaraníes. Buenos Aires: Imprenta Balmes.

Furlong, G. (Ed.). (1965). Juan de Escandón, S. J. y su Carta a Burriel (1760). Buenos Aires: Ediciones Theoria.

Garau, F. (1690). El Olimpo del sabio instruido de la naturaleza y segunda parte de las máximas políticas y morales. Valencia: Imprenta de Iayme de Bordazar.

Gil, F. M. (2010). Introducción. En De la diferencia entre lo temporal y lo eterno. Edición facsimilar (pp. XXV-LXX). Buenos Aires: Instituto Bonaerense de Numismática y Antigüedades, Bolsa de Comercio de Buenos Aires, Bolsa de Comercio de Rosario.

González Sánchez, C. A. (2003). “Lection Espiritual”. Lectores y lectura en los libros ascéticoespirituales de la Contrarreforma. En C. A. González Sánchez y E. V. Vilar (Eds.), Grafías del 
imaginario. Representaciones culturales en España y América (siglos XVI-XVIII), (pp. 272-300). México: Fondo de Cultura Económica.

González Sánchez, C. A. (2007). Homo viator, homo scribens. Cultura gráfica, información y gobierno en la expansión atlántica, siglos XV-XVII. Madrid: Marcial Pons Historia.

Gorzalczany, M. A., y Olmos Gaona, A. (2006). La biblioteca jesuítica de Asunción. Buenos Aires: Edición de los autores.

Grafton, A. (2004). El lector humanista. En G. Cavallo y R. Chartier (Eds.), Historia de la lectura en el mundo occidental, (pp. 317-371). Madrid: Taurus.

Hansen, J. A. (2000). A civilização pela palavra. En E. M. Teixeira Lopes, L. M. Feria Filho, y C. Greive Veiga (Eds.), 500 anos de educação no Brasil, (pp. 19-41). Belo Horizonte: Autêntica.

Illari, B. (2005). Villancicos, guaraníes y chiquitos: hispanidad, control y resistencia. En C. Page, $X$ Jornadas Internacionales sobre Misiones Jesuíticas: "Educación y Evangelización. La experiencia de un Mundo Mejor”, (pp. 447-459). Córdoba: Universidad Católica de Córdoba/Agencia Nacional de Promoción Científica y Tecnológica.

Julia, D. (2004). Lecturas y Contrarreforma. En G. Cavallo y R. Chartier (Eds.), Historia de la lectura en el mundo occidental, (pp. 415-467). Madrid: Taurus.

Leonhardt, C. (Ed.). (1927). Cartas Anuas de la Provincia del Paraguay, Chile y Tucumán, de la Compañía de Jesús (1609-1614). Buenos Aires: Jacobo Peuser.

Maeder, E. (2000). El martirologio Romano. Hallazgo del primer libro impreso en las misiones jesuíticas. XX Encuentro de Geohistoria Regional (Resistencia). Presentado en Resistencia. Resistencia: Instituto de Investigaciones Geohistóricas - CONICET.

Martini, M. P. (1992). Las cofradías entre los indios de las misiones jesuitas guaraníes. Archivum, XVI, 109-126.

Mathes, M. (1991). Oasis culturales en la antigua California: las bibliotecas de las misiones de Baja California en 1773. Estudios de Historia Novohispana, 10, 369-442.

Medina, J. T. (1930). Bibliografía de la lengua guaraní. Buenos Aires: Talleres s. a. Casa Jacobo Peuser, Ltda.

Melià, B. (1970). Fuentes documentales para el estudio de la Lengua Guaraní de los siglos XVII y XVIII. Suplemento Antropológico, 5, 113-161.

Melià, B. (1992). La lengua guaraní del Paraguay. Historia, sociedad y literatura. Madrid: Editorial MAPFRE.

Melià, B. (2003 [1969]). La lengua Guaraní en el Paraguay colonial. La creación de un lenguaje cristiano en las reducciones de los Guaraníes en el Paraguay. Asunción: CEPAG.

Morales, M. M. (2011). La respiración de ausentes. Itinerario por la escritura jesuítica. En G. Wilde (Ed.), Saberes de la conversión. Jesuitas, indígenas e imperios coloniales en las fronteras de la cristiandad, (pp. 31-59). Buenos Aires: SB.

Neumann, E. (2004). “Mientras volaban correos por los pueblos”: autogoverno e práticas letradas nas missões Guarani-século XVII. Horizontes antropológicos, 10 (22), 93-119.

Neumann, E. (2005). Práticas letradas Guarani: produção e usos da escrita indígena (séculos XVII e XVIII) (Tesis doctoral). Universidade Federal do Rio de Janeiro, Rio de Janeiro.

Neumann, E. (2015). Letra de Índios. Cultura escrita, comunicação e memória indígena nas Reduções do Paraguai. São Bernardo do Campo: Nhanduti Editora. 
Obermeier, F. (2018). Manuscritos descubiertos y redescubiertos de medicina y farmacia en el contexto guaraní-español de las reducciones rioplatenses en los siglos XVII y XVIII. En Jesuit colonial medicine in South America. A multidisciplinary approach, (pp. 65-102). Kiel: ChristianAlbrechts-Universität zu Kiel.

Otazú Melgarejo, A. (2006). Práctica y semántica en la evangelización de los Guaraníes del Paraguay (S. XVI-XVIII). Asunción: Centro de Estudios Paraguayos “Antonio Guasch”.

Palomo, F. (2013). Cultura religiosa, comunicación y escritura en el mundo ibérico de la Edad Moderna. En E. Serrano (Ed.), De la tierra al cielo. Líneas recientes de investigación en historia moderna, (pp. 53-88). Zaragoza: Institución "Fernando el Católico" (CSIC).

Peramás, J. M. (1791). La república de Platón y los guaraníes. Buenos Aires: Emecé Editores.

Petrucci, A. (1999). Alfabetismo, escritura, sociedad. Barcelona: Gedisa.

Petrucci, A. (2003). La ciencia de la escritura. Primera lección de paleografía. Buenos Aires: Fondo de Cultura Económica.

Plá, J. (1975). El barroco hispano guaraní. Asunción: Editorial del Centenario S.R.L.

Rama, A. (1984). La ciudad letrada. Hanover: Ediciones del Norte.

Rappaport, J., y Cummins, T. (2011). Beyond the Lettered City: Indigenous Literacies in the Andes. Durham: Duke University Press.

Rey Fajardo, J. del, y Mora, F. G. (2008). Los jesuitas en Antioquia. 1727-1767. Aportes a la historia de la cultura y el arte. Bogotá: Pontificia Universidad Javeriana.

Ruiz de Montoya, A. (1639). Tesoro de la lengua guaraní. Madrid: Por Iuan Sanchez.

Salinas, M. L. (2010). Dominación colonial y trabajo indígena. Un estudio de la encomienda en Corrientes colonial. Asunción: CEADUC.

Severi, C. (2010). El sendero y la voz: una antropología de la memoria (1o [sic]). Ciudad Autónoma de Buenos Aires: SB.

Sommervogel, C. (1892). Bibliothèque de la Compagnie de Jésus. Bruxelles-Paris: Société Belge de Libraire - Libraire des Archives nationales et de l'École des Chartes.

Steedman, C. (2007). Master and Servant. Love and Labour in the English Industrial Age. Cambridge: Cambridge University Press.

Takeda, K. (2017). The Jesuit-Guaraní Confraternity in the Spanish Missions of South America (1609-1767): A Global Religious Organization for the Colonial Integration of Amerindians. Confraternitas, 28 (1), 16-39.

Telesca, I. (2009). Tras los expulsos: cambios demográficos y territoriales en el Paraguay después de la expulsión de los jesuitas. Asunción, Paraguay: Universidad Católica "Nuestra Señora de la Asunción".

Vega, F. R. (2017). Los saberes misionales en los márgenes de la monarquía hispánica: los libros de la reducción jesuítico-guaraní de Candelaria. Archivum Historicum Societatis Iesu, LXXXVI (172), 337-386.

Vega, F. R. (2018). La dimensión bibliográfica de la reducción lingüística. La producción textual jesuítica en guaraní a través de los inventarios de bibliotecas. Nuevo Mundo Mundos Nuevos [En línea], Débats, publicado en línea el 10 de diciembre 2018. 
Wilde, G. (2014). Adaptaciones y apropiaciones en una cultura textual de frontera: impresos misionales del Paraguay Jesuítico. História Unisinos, 18 (2), 270-286.

Wilde, G. (2015). The Sounds of Indigenous Ancestors. Music, Corporality and Memory in the Jesuit Missions of Colonial South America. En P. Hall (Ed.), The Oxford Handbook of Music Censorship, (pp. 87-107). Oxford: Oxford University Press.

Wilde, G. (2017). Les modalités indigènes de la dévotion. Identité religieuse, subjectivité et mémoire dans les frontières coloniales d'Amérique du Sud. En A. Maldavsky (Ed.), Les Laïcs dans la mission. Europe et Amériques, XVIe-XVIIIe siècles, (pp. 135-180). Presses universitaires FrançoisRabelais.

Wilde, G. (2018). Invención, circulación y manipulación de clasificaciones en los orígenes de una antropología misionera. En C. Giudicelli (Ed.), Luchas de clasificación. Las sociedades indígenas entre taxonomía, memoria y reapropiación, (pp. 41-77). Rosario: Prohistoria.

Wilde, G. (2019) Regímenes de memoria misional: formas visuales emergentes en las reducciones jesuí:tícas de América del Sur. Colonial Latin American Review, 28 (1): 10-36.

Wilde, G., y Vega, F. R. (2019). De la indiferencia entre lo temporal y lo eterno. Élites indígenas, cultura textual y memoria en las fronteras de América del Sur. Varia Historia, 35 (68), 273-318.

Zabala, J. P. (Ed.). (2011). Archivo General de la Nación. Fondos Documentales del Departamento Documentos Escritos. Período Colonial. Buenos Aires: Archivo General de la Nación.

\section{NOTAS}

1. Agradecemos a Leonardo Cerno por su lectura crítica y ayuda en la traducción de los fragmentos en guaraní de este documento. Las omisiones o errores que este texto pueda tener son de nuestra exclusiva responsabilidad.

2. En un trabajo anterior delimitamos a la "cultura textual" como unidad central de análisis (Wilde y Vega, 2019). En este texto nos interesa re-enmarcar dicho concepto en la noción integradora de "cultura escrita" - tal y como la definen los autores citados-, ya que a nuestro entender esta categoría alude al mismo proyecto de descripción y análisis.

3. Buenos Aires, Archivo General de la Nación, Sala IX, 07-01-01, “Dominio despotico con esclavos, politico con iguales...", documento con número 106.

4. Agradecemos esta observación a Franz Obermeier.

5. El estudio paleográfico de la mano que interviene en el papel merecería una investigación en sí misma en vistas a rastrear la posible autoría. Cabe aquí únicamente destacar que la caligrafía es muy distinta de aquella que se percibe en muchos de los documentos redactados por indígenas de las misiones. En especial, los documentos políticos redactados por los cabildos de las misiones poseen una caligrafía muy cuidada y ordenada, que no se percibe aquí. En cualquier caso, las circunstancias de producción de esos materiales son muy especiales y seguramente fueron elaborados por los mayores profesionales de la escritura de cada reducción. Las condiciones de escritura del documento aquí estudiado son, sin duda, distintas.

6. Como sabemos, esta fue una práctica común en el espacio misional, sobre todo en ciertos momentos. La historia de las cartas y misivas aún está por hacerse, pero sabemos de la circulación de billetes y papeles en formato pequeño durante el conflicto llamado Guerra Guaranítica (Neumann, 2004, 2015, pp. 99-135).

7. A este contexto multilingüe se deben agregar los usos personales de las lenguas nativas de los jesuitas que provenían de distintas partes de Europa, de las que se han preservado preciosos exponentes. Tal es el caso de gran cantidad de cartas de jesuitas germano-parlantes a sus 
familiares centro-europeos, muchas de las cuales son desconocidas hasta el momento. El jesuita Carlos Leonhardt encaró la traducción de muchas de ellas, hoy preservadas en el archivo del Instituto Ravignani de la Facultad de Filosofía y Letras de la Universidad de Buenos Aires. Por otra parte, las obras de jesuitas como Florián Paucke (1719-1779), Martín Dobrizhoffer (1718-1791) o Antonio Sepp (1683-1733), si bien fueron trasladadas al español en el siglo XX, parecen no haber sido objeto de traducciones exactas.

8. Interpretamos la expresión mborahei (canto) (Ruiz de Montoya, 1639, f. 216r y 315v) como una exhortación imperativa dirigida a los ángeles, puesto que se ha apostrofado a estos en versos anteriores. Sin embargo, esta lectura es provisoria, porque la palabra relativa al canto carece de marcas de persona.

9. Resulta incierto si este "Ma" efectivamente pertenece a la segunda columna como aquí lo sugerimos. Como puede observarse en el original, la " $\mathrm{M}$ " es claramente diferente a la utilizada en la palabra que se encuentra debajo, "Mburubicha". A su vez, la grafía de "Ma" parece ser diferente a la del párrafo anterior. Tampoco está claro su significado. Podría tratarse de una abreviatura de mârângatu, pero no es la manera común como esta aparece en escritos de la época. Retomamos el tema en la nota 14 sobre el mismo vocablo utilizado en otro fragmento.

10. Debido a la separación entre los márgenes de un mismo renglón, resulta difícil interpretar si este fragmento constituye un discurso unificado. No obstante, mantiene cierta coherencia de conjunto.

11. Existe la posibilidad de que esta palabra sea "cheroga". En ese caso, el sentido de la frase cambiaría, como se ve más abajo.

12. La traducción alternativa, en el caso de interpretar "cheroga" en vez de "cheropa", sería: "Ojalá los de San Lorenzo [sean] mi casa".

13. En el contexto misional guaraní las pascuas son generalmente referidas como arete guazu, literalmente 'fiesta grande'.

14. Aquí interpretamos "Ma" y "Ma." como una abreviatura de mârângatu. La abreviatura podría referir también a "María", pero esa traducción no parece hacer sentido dentro de la oración.

15. Esta interpretación es relativa, puesto que la expresión mbaepe peiapone podría tratarse también de una pregunta.

16. Es ciertamente posible pensar que la mención de "S. Lorenzo" en el documento tenga un sentido hagiográfico y no geográfico, por San Lorenzo Mártir. Sin embargo, la lengua no habilita una interpretación de ese tipo. En el documento se lee claramente "S. Lorenzo igua": "(i)gua(ra)" es un sufijo que indica procedencia.

17. La manifestación más significativa de esta situación es la producción de un manuscrito lingüístico específico, Phrases Selectas, un diccionario guaraní-español escrito especialmente en función de las condiciones dialectales particulares de una región del río Uruguay. Este manuscrito incluye, por ejemplo, una sección titulada "Varios vocablos, y modos de hablar no usados en San Javier ni en Santa María, pero por si acaso fueren usados en alguna parte de estas Reducciones los quiero poner aquí...”. Buenos Aires, Museo Mitre, Biblioteca Americana, 14-4-41, Phrases selectas y modos de hablar escogidos y usados en la lengua guarani...

18. Una exploración superficial de la producción textual de la reducción de San Lorenzo sugiere que por lo menos en algunos casos esta tuvo un carácter espiritual, con un leve componente milenarista. Así, en la carta que el cabildo de San Lorenzo escribió al gobernador de Buenos Aires en 1753, en el contexto de la Guerra Guaranítica, se alude a reliquias de este santo enviadas directamente por el Papa a esta misión, y se menciona reiteradamente el "clamor" del Santísimo Sacramento y el amor de la Virgen María. Respecto de los jesuitas y la guerra, en esta carta llega a decirse que: "[n]o nos apartaremos de ellos ni los echaremos ni dexaremos ir, como nros, quedaran echos zeniza debaxio delos pies del SS.mo Sacram.to y de S. Lorenzo, finalm.te y despues de esto tu mismo [el gobernador] haras sacar el SS.mo Sacram.to de nra Igl.a". 
Transcripción disponible en línea en: LANGAS (2012-), Corpus diacrónico del guarani en línea (XVI-XIX). http://www.langas.cnrs.fr/ (consultado 30/04/19).

19. En las misiones, la repetición por parte de miembros de la élite indígena de sermones inicialmente verbalizados por un jesuita era una práctica común, según lo muestran cartas relatorias de José Cardiel y Juan Escandón (Furlong, 1953, pp. 175-176, 1965, p. 96).

20. EL OLIMPO / DEL SABIO / INSTRVIDO DE LA NATVRALEZA, / Y SEGVNDA PARTE / DE LAS MAXIMAS POLITICAS, / Y MORALES, / ILLVSTRADAS / CON TODO GENERO DE ERVDICION / SACRA, Y HVMANA. / POR EL R. P. FRANCISCO GARAV / de la Compañia de Iesvs, Catedratico de Teologia en / el Colegio de Barcelona; y aora Retor / en el de Mallorca. / DEDICADO / AL SEÑOR / DON GASPAR DE ROCAFVLL Y ROCABERTI, / Maeftre de Campo de Infanteria Elpañola en el Erercito de / Flandes, y tres vezes Gobernador de las Guardias / en el milmo Paìs. / Và à la fin un Indice de Materias Predicables. / Pliegos CON LICENCIA 67. / [Filete] / EN VALENCIA: En la Imprenta de IAYME DE BORDAZAR Año 1690. / A expenfas de Alenfio Duarte.

21. La edición de 1681 carece de los clásicos grabados de emblemas y es poco probable que hubiera alcanzado el Paraguay jesuítico. Todo indica que su tirada fue escasa, inferior a las posteriores. Una sencilla búsqueda en Worldcat, el mayor catálogo digital del mundo, arroja la existencia de tan solo tres ejemplares impresos en 1681 en las bibliotecas registradas. Disponible en línea: https://www.worldcat.org/ (consultado 30/04/19).

22. AGN, Sala IX, 22-06-03, "De los Santos Apóstoles San Pedro y San Pablo. Testimonio de lo actuado para el extrañamiento, y ocupación de temporalidades", cuadernillo n²9; "Concepción. Testimonio de las diligencias actuadas en el pueblo de la Concepción de indios guaraníes”, n¹4; "Itapúa. Testimonio de las diligencias actuadas en el pueblo de Nuestra Señora de la Encarnación, nombrado Itapúa", n¹7; "Santos Mártires. Compulsa de los autos de inventario de los bienes secuestrados a los regulares de la Compañía de Jesús", n incomprensible; "San Cosme. Testimonio de los autos de inventarios, extrañamiento y ocupación de temporalidades de los regulares de la Compañía", n5; "San Ignacio Mirí. Testimonio de las diligencias actuadas en el pueblo de San Ignacio Mirí de indios guaraníes”, n²4; "Pueblo de San José. Testimonio de los autos de inventarios, extrañamiento y ocupación de temporalidades", n²8; "San Juan Bautista. Testimonio de las diligencias actuadas para el extrañamiento y ocupación de temporalidades de los regulares de la Compañía", n¹; "Pueblo de San Lorenzo. Testimonio de lo actuado para el extrañamiento y ocupación de temporalidades de los regulares de la Compañía", n¹6; "Yapeyú. Testimonio de las diligencias actuadas en el pueblo de Nuestra Señora de los Reyes de Yapeyú", n²7. También: AGN, Sala IX, 22-06-04, "Santo Ángel. Testimonio de lo actuado para el extrañamiento y ocupación de temporalidades de los regulares de la Compañía”, cuadernillo n²0 y AGN, Sala IX, 17-03-06, "Reconocimiento de la Libreria nombrada del Padre Superior de Misiones en este Pueblo de la Candelaria".

23. La transcripción exacta del fragmento, a partir del libro, sería: “Assi, pues, manda despoticamente al cuerpo, como á su esclavo, el alma: politicamente á la voluntad, como á su compañera, el entendimiento: y assi armada la voluntad, impera, como Reyna, á la parte concupiscible, é irascible, y demás passiones inferiores, como á sus subditos" (Garau, 1690, p. 437).

24. La imitación y el símbolo del espejo como reflejo de la misma constituyen motivos comunes en la iconografía y la literatura emblemática. Al respecto, resultan útiles los materiales compilados en la sección "Emblemática" de la Biblioteca Digital Siglo de Oro, coordinada por Nieves Pena Sueiro y Sagrario López Poza. Disponible en línea: https://www.bidiso.es/Emblematica/ (consultado 30/04/19).

25. Es posible que los fragmentos en guaraní no sean originales sino también citas de otros textos en ese idioma. Sin embargo, actualmente no existe un corpus exhaustivo y digitalizado de la producción textual en este idioma, sino solo proyectos parciales. El más relevante es LANGAS, dirigido por Capucine Boidin y citado en una nota anterior. 
26. Tal fenómeno de imbricación de registros espirituales y temporales se ve reflejado en evidencias marginales imprevisiblemente anotadas en documentos de diferente tipo. Recientemente hemos identificado, en un libro de cuentas de las misiones - un documento eminentemente económico-, una transcripción de por lo menos algunas partes del Trisagio a la Santísima Trinidad, que ameritaría un estudio específico. En el documento, el texto está escrito en tres columnas, que aquí separamos con el símbolo " |": "El yris que en el mar / la tierra y en el fuego / el ayre ostenta luego / nos quiere libertar / favor tan singular / este prodigio y encanto / Angeles, y Serafines / dicen Santo Santo Santo / Es escudo soberano / de la Justicia Divina / y de la infernal / malicia / triunfa devoto el cristiano / y como el Demonio ufano / huye de terror y espanto / Angeles y Serafines / dicen Santo Santo Santo. | En Vuestra Bondad me fundo / ser Dios Fuerte, e inmortal / que en el Coro Celestial / cantaré este Himno fecundo / pues en los riesgos del mundo / me cubres con vuestro manto / Angeles y Serafines / dicen Santo Santo Santo / Dios Uno, y Trino a quien tantos." (subrayados en el original). Asunción, Archivo Nacional de Asunción, SNE, Vol. 218, Estado de cuentas sobre ganados y otros bienes administrativos de los ex pueblos jesuíticos del Paraná: “de marzo de 1788 Corregidor hae Administrador oivépe [ilegible] charamo orombe...", f. 113r.

27. El proyecto de inventario tiene por objetivo dar a conocer la totalidad del corpus, incluyendo materiales de los siglos XVII, XVIII y XIX.

28. Un fenómeno adicional que contribuye al ocasional desconocimiento de fuentes efectivamente existentes es el que podríamos definir como casos de "documento encapsulado", es decir, textos o fragmentos de textos que aparecen citados dentro de documentos de diferente tipo, por ejemplo, expedientes judiciales y mapas, que pueden incluir transcripciones completas de cartas escritas en guaraní por indígenas.

29. La circulación de textos entre las misiones de guaraníes y de chiquitos es un hecho constatado aunque poco estudiado hasta el momento (Maeder, 2000).

30. Debe tenerse en cuenta que existieron ejemplos de escritura expuesta en papel durante el conflicto conocido como "guerra guaranítica" y que eventualmente la escritura en soportes diferentes del papel, por ejemplo en cuero o madera, pudiera ser de carácter "privado".

31. Seguimos las reglas tradicionales de la transcripción paleográfica en lo que concierne a los fragmentos en castellano y latín, de modo que desarrollamos las abreviaturas y modernizamos el uso de mayúsculas y minúsculas pero mantenemos la ortografía original. La inexistencia de una filología del guaraní antiguo nos impide seguir reglas específicas en la transcripción. Por esta razón, seremos lo más fieles posibles al documento original. Esto implica que no desarrollamos las abreviaturas ni modificamos el uso de mayúsculas y minúsculas. Desde luego, mantenemos la ortografía específica (e inestable) del guaraní colonial; no nos valemos de la modernización al guaraní paraguayo actual. Por lo demás, utilizaremos el símbolo "|" para distinguir entre textos que figuran en los márgenes opuestos de un mismo renglón, mientras que usamos el símbolo "/" para dividir los renglones.

32. Esta expresión está ausente en el versículo de la Vulgata.

33. La traducción de los fragmentos bíblicos de la Vulgata se basa en la traducción literal realizada por Felipe Scío de San Miguel (1738-1796). Aunque remitimos a los versículos correspondientes, no los transcribimos directamente, porque en el documento original existen omisiones e intercalaciones. 


\section{RESÚMENES}

Este artículo analiza un enigmático documento encontrado en el Archivo General de la Nación de Buenos Aires. Se trata de un pequeño folio escrito en recto y verso que contiene fragmentos de texto en tres lenguas: guaraní, español y latín. Tratamos de entender sus posibles usos en la cultura escrita de la provincia jesuítica del Paraguay y más ampliamente en la praxis políticoreligiosa de los pueblos de misión, compartida por los misioneros jesuitas y los miembros de la elite indígena. Argumentamos que este documento señala una imbricación entre la dimensión espiritual y temporal de la vida misional y da indicios de lo que pudo ser el desenvolvimiento de la performance verbal en esos espacios, íntimamente ligada a las prácticas devocionales. Al tiempo que indagamos en las características singulares de este enigmático papel, buscamos encontrarle sentido dentro de un corpus más amplio. La primera parte del artículo aborda las características materiales específicas del documento. La segunda se centra en el análisis del contenido de cada uno de los fragmentos en las tres lenguas. Las tercera y cuarta partes sitúan el escrito respectivamente en sus posibles contextos de uso y su trama intertextual.

This article analyses an enigmatic document found at Buenos Aires National Archive. It is a small folio written on recto and verso containing text excerpts in three languages: Guarani, Spanish and Latin. We try to understand possible uses of this document in the context of missionary written culture of the Jesuit province of Paraguay shared both by the Jesuit missionaries and the members of the Indigenous elite, while broadly exploring the political and religious praxis of the Guarani mission towns. We argue that this document points to an imbrication between the spiritual and temporal dimensions of mission's daily life. It also provides evidence of what could have been the development of verbal performance in these spaces, closely linked to devotional practices. While we inquire into the singular characteristics of this enigmatic paper, we try to find its meaning in the framework of the broader corpus. The first part of the article studies specific material characteristics of the document. The second focuses on the analysis of the content of each excerpt in the three languages. The third and fourth parts situate the document respectively in its possible contexts of use and its intertextual weave.

\section{ÍNDICE}

Palabras claves: Cultura escrita, lengua guaraní, misiones jesuíticas, literatura emblemática, Paraguay.

Keywords: Written culture, Guarani language, Jesuit missions, emblematic literature, Paraguay.

\section{AUTORES}

\section{FABIÁN R. VEGA}

Consejo Nacional de Investigaciones Científicas y Técnicas, Instituto de Altos Estudios SocialesUniversidad Nacional de San Martín y Universidad de Buenos Aires, Argentina. Correo electrónico: vegafabianr@gmail.com

\section{GUILLERMO WILDE}

Consejo Nacional de Investigaciones Científicas y Técnicas e Instituto de Altos Estudios SocialesUniversidad Nacional de San Martín, Argentina. 
Correo electrónico: guillermowilde@gmail.com 